Silvia Takanohashi Kobayashi

\title{
Avaliação da implantação do Fluxo Gerenciado FGC20, modelo de gerenciamento do protocolo clínico institucional para o tratamento neoadjuvante de adenocarcinoma de reto
}

Dissertação apresentada à Faculdade de Medicina da Universidade de São Paulo para a obtenção do título de Mestre em Ciências

Programa de Oncologia

Orientadora: Dra Maria Del Pilar Estevez Diz

São Paulo

2016 
Dados Internacionais de Catalogação na Publicação (CIP)

Preparada pela Biblioteca da

Faculdade de Medicina da Universidade de São Paulo

Creprodução autorizada pelo autor

Kobayashi, Silvia Takanohashi

Avaliação da implantação do fluxo gerenciado FGC20, modelo de gerenciamento do protocolo clínico institucional para o tratamento neoadjuvante de adenocarcinoma de reto / Silvia Takanohashi Kobayashi. -- São Paulo, 2016.

Dissertação(mestrado)--Faculdade de Medicina da Universidade de São Paulo. Programa de Oncologia.

Orientadora: Maria Del Pilar Estevez Diz.

Descritores: 1.Neoplasias retais 2.Protocolos clínicos 3.Custos e análise de custo 4.Terapia neoadjuvante 5.Sobrevida

USP/FM/DBD-273/16 


\section{DEDICATÓRIA}

Ao meu filho Eiki, Meu amor incondicional.

Ao meu marido Sérgio,

Nossa cumplicidade, amor, companheirismo e incentivo mútuo.

Aos meus Pais, Osamu e Alzira Minha eterna gratidão. 


\section{AGRADECIMENTOS}

Meus sinceros agradecimentos a todos que apoiaram a execução deste trabalho, em especial:

à Dra Maria Del Pilar Estevez Diz, orientadora aplicada, competente, minuciosa, paciente, e sobretudo, grande amiga,

ao Prof Roger Chammas, um grande incentivador e o responsável pelo despertar de meu interesse científico,

ao Prof Paulo Hoff, força motriz da assistência oncológica, meu orientador inicial e o grande viabilizador deste estudo,

à Prof Patrícia Coelho De Soárez, Prof Ulysses Ribeiro Jr, Dr Alessandro Gonçalves Campolina e Dra Rossana Veronica Mendoza Lopez pelo grande apoio em todas as etapas deste trabalho,

À Diretoria Executiva do ICESP, e todos os seus diretores e assistentes,

A todos os profissionais do ICESP, médicos, odontólogos, físicos, enfermeiros, nutricionistas, fisioterapeutas, psicólogos, assistentes sociais, gerentes, coordenadores, supervisores, assistentes administrativos e oficiais administrativos, meus grandes companheiros de trabalho envolvidos direta ou indiretamente no tratamento dos pacientes,

Aos pacientes participantes deste estudo, e seus familiares. 


\section{SUMÁRIO}

\section{LISTA DE ABREVIATURAS}

\section{LISTA DE TABELAS}

LISTA DE FIGURAS

RESUMO

\section{ABSTRACT}

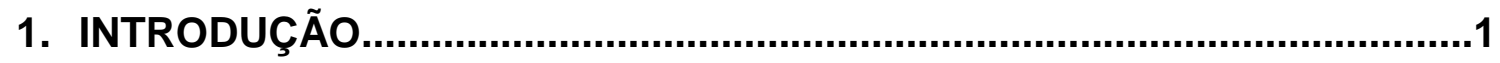

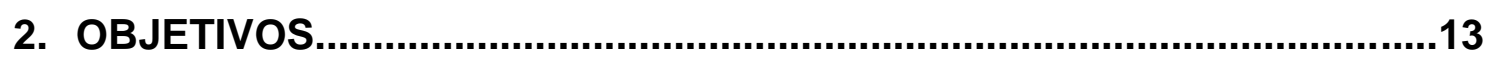

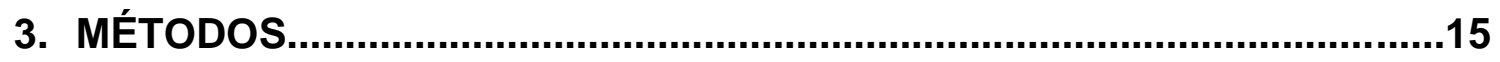

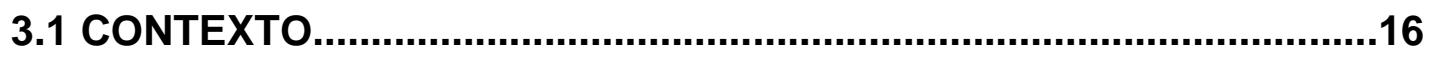

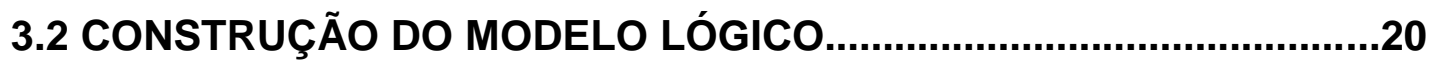

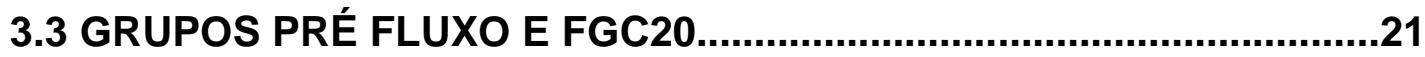

3.4 MENSURAÇÃO DOS INTERVALOS DE TEMPO................................23

3.5 MENSURAÇÃO DOS RECURSOS, CUSTOS E SOBREVIDA.............24

3.6 ANÁLISE ESTATÍSTICA...............................................................31

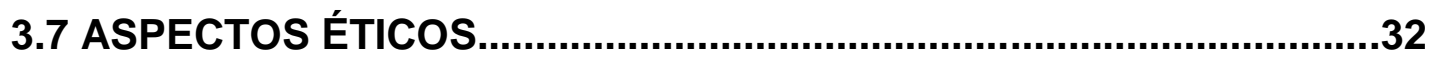

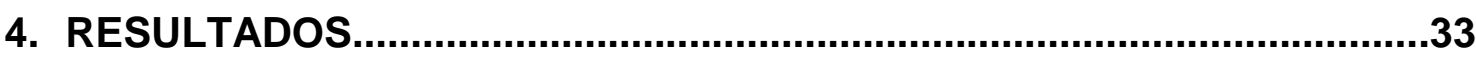

4.1 MODELO LÓGICO DO FGC20 ............................................................34

4.2 AVALIAÇÃO DOS INTERVALOS DE TEMPO E INDICADORES DE MONITORAMENTO DE RESULTADOS DO MODELO LÓGICO...........41

4.3 AVALIAÇÃO DOS RECURSOS UTILIZADOS E DESCRIÇÃO DE CUSTOS DO TRATAMENTO DO CÂNCER DE RETO..........................47

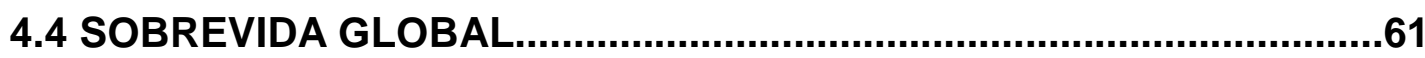

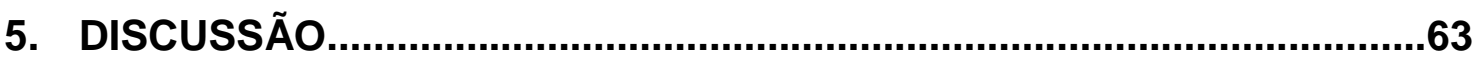

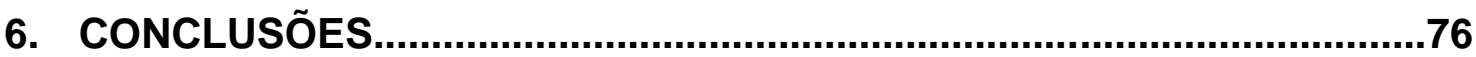

7. SUGESTÕES PARA TRABALHOS FUTUROS.......................................78

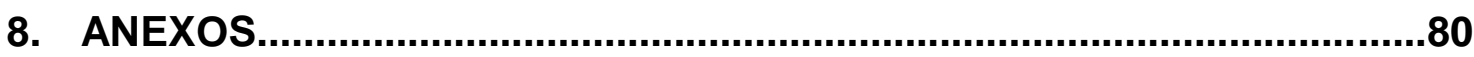

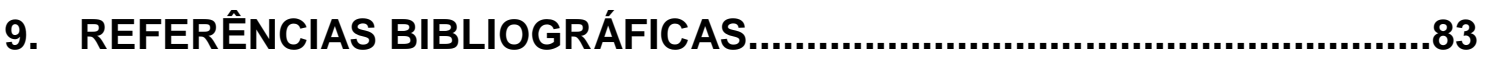




\section{LISTA DE ABREVIATURAS}

\section{AJCC: American Joint Committee on Cancer}

CAIO: Centro de Atendimento às Intercorrências Oncológicas

CATE: relatórios desenvolvidos pelo cliente, C:cliente, ATE: atendimento

CID: Classificação Estatística Internacional de Doenças e Problemas Relacionados com a Saúde, 10ª edição

EP: erro padrão

FGC20: Fluxo Gerenciado FGC20

Flag: alerta no prontuário eletrônico identificando o paciente como pertencente ao Fluxo Gerenciado FGC20

FULV: protocolo de quimioterapia com ácido folínico $\left(20 \mathrm{mg} / \mathrm{m}^{2}\right.$, IV, bolus D1a D5) e 5 -fluorouracil $\left(350 \mathrm{mg} / \mathrm{m}^{2}\right.$, IV, bolus D1 a D5) nas semanas 1 e $5 \mathrm{da}$ radioterapia

h: horas

IC95\%: intervalo de confiança de 95\%

ICESP: Instituto do Câncer do Estado de São Paulo

InRad: Instituto de Radiologia do Hospital das Clínicas da Faculdade de Medicina da Universidade de São Paulo

mFLOX: protocolo de quimioterapia com oxaliplatina $\left(85 \mathrm{mg} / \mathrm{m}^{2} \mathrm{IV} 2\right.$ horas, semanas 1,3,5), ácido folínico (20 mg/ $\mathrm{m}^{2} \mathrm{IV}$ bolus, semanas 1,2,3,4,5,6) e 5fluorouracil (500 mg/ $\mathrm{m}^{2}$ IV bolus, semanas 1,2,3,4,5,6)

$\mathrm{m}^{2}$ : metros quadrados

min: minutos

$\mathrm{nCRT}$ : quimioterapia e radioterapia neoadjuvantes

PRÉ FLUXO: Período prévio à implantação do Fluxo Gerenciado FGC20

QUASAR: protocolo de quimioterapia com ácido folínico (50 mg IV, semanal) e 5-fluorouracil ( $370 \mathrm{mg} / \mathrm{m}^{2} \mathrm{IV}$, semanal)

QT: quimioterapia 
RM: ressonância magnética

$\mathrm{RT}$ : radioterapia

$\mathrm{RX}$ tórax: radiografia de tórax

TC: tomografia computadorizada

TNM: Sistema de estadiamento: T: tumor, N: linfonodo, M: metástase

UI: unidade de Internação

UTI: unidade de Terapia Intensiva

Vmin: valor mínimo

Vmax: valor máximo 


\section{LISTA DE TABELAS}

Tabela 1. Distribuição, dados demográficos, estádio clínico inicial, inicial agrupado e patológico de pacientes observados nos PRÉ FLUXO e FGC20, em pacientes com câncer de reto, ICESP, 20082013 44

Tabela 2. Indicadores de monitoramento do Modelo Lógico do FGC20 e intervalos entre as etapas de primeira consulta médica, tratamento neoadjuvante e cirurgia, em pacientes com câncer de reto, ICESP, 20112013.

Tabela 3. Recursos utilizados no período entre a primeiro atendimento médico e 30 dias após a cirurgia, dos pacientes com câncer de reto observados nos grupos PRÉ FLUXO e FGC20, ICESP, 2008-2013, e valores unitários de custos por recursos, referência jan-jul 2015. 48

Tabela 4. Distribuição de eventos de atendimentos, média de eventos e de dias de internação no CAIO, Unidades de Internação e Unidade de Terapia Intensiva, no período entre a primeiro atendimento médico e 30 dias após a cirurgia, dos pacientes com câncer de reto observados nos grupos PRÉ FLUXO e FGC20, ICESP, 2008-2013 49

Tabela 5. Valores unitários de custos de diárias, referência jan-jul 2015, ICESP. .50

Tabela 6. Utilização de quimioterapia no período entre a primeiro atendimento médico e 30 dias após a cirurgia, pelos pacientes com câncer de reto, observados nos grupos PRÉ FLUXO e FGC20, ICESP, 20082013 .51

Tabela 7. Custo em Reais de junho 2015, quimioterapia protocolo mFLOX e protocolo FULV, ICESP 52

Tabela 8. Custo do procedimento cirúrgico, ICESP, referência minuto cirúrgico jan-jul 2015, ICESP

Tabela 9. Custo por paciente tratado, segundo Grupo PRÉ FLUXO e FGC20, ICESP, 2008-2013

Tabela 10. Recursos utilizados e custos do tratamento dos pacientes com câncer de reto, em Reais de jan-jul 2015, nos grupos PRÉ FLUXO e FGC20, ICESP, 2008-2013 .59

Tabela 11. Tempo médio de sobrevida global, em anos, nos grupos PRÉ FLUXO e FGC20, ICESP. 


\section{LISTA DE FIGURAS}

Figura 1. Diagrama do Fluxo Gerenciado FGC20, ICESP, 2011 19

Figura 2. Modelo lógico da implantação Fluxo Gerenciado FGC20, ICESP

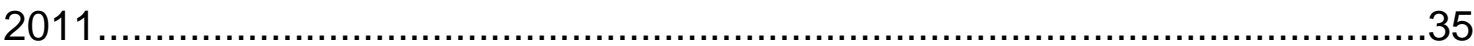

Figura 3. Descritivo de pacientes com câncer de reto observados 2008-2013, ICESP 42

Figura 4. Gráfico de boxplot dos custos segundo PRÉ FLUXO e FGC20, ICESP 2008-2013

Figura 5. Distribuição dos agrupamentos de custos, grupos PRÉ FLUXO e Fluxo Gerenciado FGC20, ICESP 2008-2013...... 60

Figura 6. Curva de sobrevida global nos grupos PRÉ FLUXO e FGC20, ICESP. 62 


\section{RESUMO}

Kobayashi ST. Avaliação da implantação do Fluxo Gerenciado FGC20, modelo de gerenciamento do protocolo clínico institucional para o tratamento neoadjuvante de adenocarcinoma de reto [Dissertação]. São Paulo: Faculdade de Medicina, Universidade de São Paulo; 2016.

Introdução. O Fluxo Gerenciado FGC20 é um protocolo institucional que define as etapas do tratamento neoadjuvante para adenocarcinoma de reto, com quimioterapia e radioterapia concomitantes e posterior cirurgia. Sua implantação no Instituto do Câncer do Estado de São Paulo (ICESP), a partir de março de 2011, envolveu as áreas assistenciais médicas, multiprofissionais e administrativas, com o estabelecimento da sequência das etapas e intervalos desejáveis. Objetivos. Avaliar a implantação do modelo de gerenciamento do protocolo clínico institucional para o tratamento neoadjuvante do adenocarcinoma de reto, nomeado Fluxo Gerenciado FGC20, adotado no ICESP. Pacientes e métodos. Foi construído um modelo lógico operacional para descrever o processo de implantação do fluxo gerenciado FGC20. Indicadores de monitoramento foram definidos a partir do modelo lógico e comparados com o período prévio à implantação. Dois grupos foram comparados: grupo controle, de pacientes cuja entrada ocorreu entre 06/05/2008 a 11/05/2011 (prévio à implantação, nomeado grupo PreFluxo); e grupo experimental, de pacientes com início de atendimento entre 12/05/2011 a 31/12/2013 (posterior à implantação, nomeado grupo FGC20). Foram incluídos pacientes consecutivos, com diagnóstico de câncer de reto, tratados com quimioterapia e radioterapia concomitantes e posterior realização de cirurgia, e excluídos pacientes metastáticos ao diagnóstico inicial, pacientes com tratamento prévio ao início do tratamento no serviço e pacientes que não realizaram o tratamento neoadjuvante. Foram observados os intervalos de tempo entre as etapas do tratamento e recursos utilizados, dentre consultas, exames, internações, quimioterapia, radioterapia e cirurgia. O estudo de descrição de custos foi apresentado em Reais de 2015 na perspectiva do serviço. Resultados. De um total de 624 pacientes, foram analisados 330 pacientes: 112 do grupo PréFluxo e 218 do grupo FGC20. Em relação aos indicadores de monitoramento da implantação, $66 \%$ dos pacientes do grupo FGC20 realizaram a $1^{\text {a }}$ consulta no intervalo $\leq 15$ dias, $75 \%$ dos pacientes ficaram dentro da meta esperada de 14 semanas para o intervalo entre o final da neoadjuvância e a cirurgia (mediana de 13,2 semanas grupo FGC20 e 20 semanas grupo PréFluxo) e $73 \%$ dos pacientes completaram todas as etapas do fluxo gerenciado no intervalo $\leq 189$ dias (mediana de 176,4 dias grupo FGC20 e 261,5 dias grupo PréFluxo). No grupo PréFluxo, houve maior número de consultas com oncologistas clínicos, tomografias computadorizadas, ressonâncias magnéticas e sessões de radioterapia $(p<0,001)$, bem como maior média de eventos de passagens no Setor de Emergência e na Unidade de Terapia Intensiva, em relação ao grupo FGC20 $(p<0,001)$ e a média de custo por paciente tratado no grupo PréFluxo foi de $\mathrm{R} \$ 40.935,68$ e mediana de $R \$ 37.948,05$. No grupo Fluxo Gerenciado, a média de custo por paciente tratado foi de $R \$ 40.368,18$ e a mediana de $R \$ 35.341,32$ respectivamente. A média de sobrevida global foi de 5,99 $(5,59-6,40)$ e de 7,01 $(6,47-7,54)$ anos, para os grupos PreFluxo e FGC20, respectivamente $(p=0,83)$. Conclusões. A implantação do fluxo gerenciado promoveu reduções em todos os intervalos de tempo entre as etapas do tratamento. Não houve diferenças estatisticamente significantes na sobrevida global e no custo por paciente tratado entre os grupos. Custos de diárias e consultas foram os segmentos mais representativos no custo total do tratamento do paciente com câncer de reto.

Descritores: neoplasias retais; protocolos clínicos; custos e análise de custo; terapia neoadjuvante; sobrevida. 


\section{ABSTRACT}

Kobayashi ST. Integrated care pathway for rectal cancer: implementation evaluation [Dissertation]. São Paulo: "Faculdade de Medicina, Universidade de São Paulo"; 2016.

Background. The FGC20 is an integrated care pathway started in May 2011 at Instituto do Cancer do Estado de Sao Paulo (ICESP) for neoadjuvant treatment of adenocarcinoma of rectum. The implementation involved a multidisciplinary team to standardize patient care and to define steps, interventions and goals. Objectives. To evaluate the implementation of a clinical care pathway of rectal cancer in a Brazilian tertiary academic oncology hospital. Patients and Methods: An operational logical model of the integrated care pathway was developed to describe the pathway implementation. Two cohorts of diagnosed rectal cancer patients were compared: a control cohort from May 06 ${ }^{\text {th }}, 2008$ through May $11^{\text {th }}, 2011$ (before the implementation, named group Pre FGC20), and a cohort from May $12^{\text {th }}, 2011$ through December $31^{\text {th }}, 2013$ (after implementation, named group FGC20). We included consecutive patients treated with concomitant chemoradiotherapy (nCRT) followed by surgery. Patients with prior treatment or who have not performed the nCRT treatment or with metastatic disease at diagnosis were excluded. Time intervals between treatment steps and resources used, including consultations, exams, hospitalizations, chemotherapy, radiotherapy and surgery were assessed. Cost description study from the hospital perspective is presented in 2015 Reais. Results. From a total of 624 patients, 330 were included: 112 PreFGC20 and 218 FGC20. Implementation indicators of the group FGC20 were identified based on the logic model: $66 \%$ had the first consultation $\leq 15$ days, $75 \% \leq 14$ weeks interval between the neoadjuvant treatment and surgery (Group PreFGC20: 20 weeks, median; group FGC20: 13.2 weeks, median) and $73 \% \leq 189$ days to complete all treatment steps (Group PreFGC20: 261.5 days, median; group FGC20: 176.4 days, median). We found higher utilization of consultations with clinical oncologists, CT, MRIs and radiotherapy sessions in the Group PreFGC20 compared with the FGC20 Group ( $p<0.001)$, and also more utilization of emergency room and intensive care unit in Group PreFGC20 ( $p<0.001)$. Median cost per treated patient in Group PreFGC20 was $R \$ 37.948,05$ and mean cost was $R \$ 40.935,68$. Median cost per treated patient in Group FGC20 was $R \$ 35.341,32$ and mean cost was $R \$ 40.368,18$. The mean overall survival in the Pre-MFC20 group and MFC20 group were 5.99 (5.59-6.40) and 7.01 (6.47-7.54) years, respectively $(p=0.83)$ Conclusions. The implementation of the ICP promoted reductions in all time intervals between treatment steps. There were no statistically significant difference in overall survival and cost per patient treated between the groups. Daily costs and consultations were the most representative segments in total cost of the rectal cancer patient treatment.

Descriptors: rectal neoplasms; clinical protocols; costs; neoadjuvant therapy; survivorship. 
INTRODUÇÃO 


\section{INTRODUÇÃO}

Hospital é uma organização complexa, fundamental para a prestação de serviços de saúde e formação de pessoas, e em constante processo de redefinição do seu papel enquanto produção do cuidado, busca da qualidade, eficiência e controle de custos.

Dentro do hospital, a atenção depende da conjugação do trabalho de vários profissionais. O cuidado recebido pelo paciente é produto de pequenos cuidados parciais, que vão se complementando, explícita ou implicitamente, a partir da interação entre os vários cuidadores que operam no hospital. Assim, uma complexa trama de atos, procedimentos, fluxos, rotinas, saberes, num processo de complementação e disputa, compõem o cuidado em saúde. Ou seja, a forma como se articulam as práticas dos trabalhadores do hospital confere maior ou menor integralidade à atenção produzida ${ }^{1}$.

Atualmente, um dos desafios do processo gerencial hospitalar é a coordenação deste conjunto diversificado, especializado, fragmentado de atos individuais, de modo que eles resultem em um cuidado eficaz e de qualidade ${ }^{2}$.

Neste contexto, os protocolos clínicos gerenciados surgem como uma iniciativa que procura associar evidência científica à prática clínica disponível, através de recomendações, processos e definições de prazos para a abordagem de condições médicas específicas ou intervenções. O protocolo detalha os passos essenciais no manejo de pacientes com um dado problema clínico, através de um plano estruturado e multidisciplinar ${ }^{3}$, que permite o 
estabelecimento de responsabilidades entre os profissionais, assegura 0 melhor uso do recurso, reduz espera entre as fases de tratamento, favorece a coordenação entre as especialidades envolvidas e propicia a continuidade do cuidado $^{4,5}$. Gera consistência no suporte e aumenta a colaboração entre as equipes, por fazer o mapeamento do processo do paciente e definir atores, atividades, tempo, locais e objetivos corretos visando uma meta final específica.

Estudos fazem referência à necessidade de protocolos para melhoria da qualidade da assistência, auxílio na redução de custos e otimização de recursos $^{6}$, porém, há poucas evidências que mensurem a efetividade dos mesmos e justifiquem a sua adoção.

Revisão sistemática feita por Allen e Rixson ${ }^{7}$, em 2008, avaliou o impacto dos protocolos clínicos gerenciados no cuidado de pacientes com acidente vascular cerebral. Os autores concluíram que há alguma evidência de que os protocolos proporcionem elementos para a integração de serviços, resultante da implantação da intervenção clínica no tempo correto, sem aumentar o tempo de permanência hospitalar. Referiram indícios de melhorias na documentação, porém sem mensuração dos resultados desta documentação na prática propriamente dita.

Efeitos dos protocolos na prática profissional, desfechos clínicos, taxa de permanência hospitalar e custos hospitalares foram objeto de estudo de Thomas et $\mathrm{al}^{3}$, em 2009. Nesta revisão sistemática de 27 estudos, foi demonstrado que protocolos clínicos estão associados à redução das complicações intra-hospitalares e melhoria da documentação, sem evidências 
de diferenças em readmissões hospitalares ou mortalidade intra-hospitalar. Apesar de os estudos relatarem diminuições significativas de taxa de permanência hospitalar e custos hospitalares, a heterogeneidade dos dados impediu a realização de meta-análise, e não houve conclusões em relação a estes dados.

A necessidade de desenvolver sistemas de avaliação da efetividade das equipes, bem como verificar a concordância entre as diversas decisões e implantação do tratamento ${ }^{8}$ foram apontadas por Cervantes et al, em 2007. Fatores críticos como falhas na comunicação, atrasos em intervalo de tratamento e falta de coordenação entre as especialidades envolvidas ${ }^{9}$ foram elencados por Gallego-Plazas et al, em 2009.

Estudo feito no sistema público em Alberta, Canadá, ao avaliar o padrão de aderência às diretrizes do protocolo de tratamento do adenocarcinoma de reto nos estádios II e III, encontrou dificuldades no acompanhamento e falta de consultas com oncologistas, principalmente relacionadas à idade avançada do paciente, comorbidades e localização de sua residência ${ }^{10}$.

Concentrar o cuidado em equipes multidisciplinares foi a recomendação adotada no Reino Unido, com a implantação do plano de Calman-Hine ${ }^{11}$, que delineou uma reforma nos serviços de câncer do Reino Unido, com o objetivo de melhorar os desfechos e diminuir as desigualdades no cuidado de pacientes com câncer do National Health Service. Posteriormente, para verificar o impacto da implantação das equipes em relação à melhoria de processos e desfechos, foi realizada uma avaliação longitudinal de 13 equipes em Yorkshire em estudo retrospectivo em base populacional de pacientes com câncer 
colorretal diagnosticados e tratados entre 1995 e 2000 . Houve variabilidade da adesão das equipes às recomendações do plano de Calman-Hine, e as melhorias em processos e desfechos foram diretamente relacionadas ao grau de implantação do plano. Foi observado aumento na aderência ao manual de condutas do serviço associado a aumento de taxa de sobrevida em cinco anos, ajustada a fatores como idade, estádio, status socioeconômico e ano de diagnóstico, especialmente em câncer de cólon.

Estudos de avaliação, como os citados anteriormente, auxiliam a verificar quais atividades foram implantadas conforme o planejamento, e também permitem identificar as forças, fraquezas e necessidades de melhorias. A avaliação constitui um dos melhores mecanismos para responder às necessidades de informação dos decisores, que devem justificar suas escolhas para públicos cada vez mais exigentes ${ }^{12}$. "Avaliar, segundo Brousselle et al ${ }^{13}(2011)$, consiste fundamentalmente em emitir um juízo de valor sobre uma intervenção, implementando um dispositivo capaz de fornecer informações cientificamente válidas e socialmente legítimas sobre essa intervenção ou sobre qualquer um de seus componentes, com o objetivo de proceder de modo a que os diferentes atores envolvidos, cujos campos de julgamento são por vezes diferentes, estejam aptos a se posicionar sobre a intervenção para que possam construir individual ou coletivamente um julgamento que possa se traduzir em ações."

No campo da saúde e da avaliação, a área temática multidisciplinar de "pesquisa em serviços de saúde" foi objeto de extensa revisão da literatura realizada por Novaes $^{14}$, em 2004, que descreveu, a partir dos anos 50, nos 
países desenvolvidos, o reconhecimento da necessidade de estudos sobre serviços de saúde, tanto na perspectiva "interna" - conhecer os processos de atenção neles desenvolvidos e seus efeitos sobre a saúde e a doença dos pacientes atendidos -, como na "externa" - conhecer o seu desempenho e participação na conformação dos sistemas de saúde e seu impacto sobre a saúde da população. Citou o fortalecimento do discurso da necessidade de maior integração entre o conhecimento clínico, epidemiológico e de planejamento e gestão no final da década de 80 , e na década de 90 , o surgimento de pesquisa em serviços de saúde, principalmente nos países desenvolvidos, com uma possível categorização das iniciativas segundo a dimensão de atuação: as tecnologias de produto (pesquisa e desenvolvimento de medicamentos, imunobiológicos e equipamentos considerados essenciais para a saúde) ou de processos (sistemas, serviços e profissionais de saúde).

Para se avaliar uma intervenção, é preciso começar por definí-la. Seja ela um programa ou uma política, pode ser concebida com um sistema organizado de ação que inclui, em um determinado ambiente: agentes, estrutura, processos e objetivo. A ação é o produto de longas cadeias causais que colocam em relação o conjunto das estruturas, dos processos e dos resultados. Um recurso que possibilita explicitar os vínculos entre uma intervenção e seus efeitos é a modelização. A modelização é uma etapa essencial para que sejam feitas as perguntas certas, para que os efeitos sejam atribuídos a mecanismos específicos e, assim, a avaliação possa auxiliar a tomada de decisões ${ }^{13}$. 
A modelização é uma abordagem recente, e o histórico é relatado por Brousselle et al ${ }^{13}(2011)$ : cita que as primeiras reflexões iniciaram com Weiss ${ }^{15}$ (1972), ressaltando a necessidade de conceituar as relações entre um programa e seus efeitos como a primeira etapa de uma avaliação. Posteriormente, autores como Wholey $^{16}$ (1987), abordaram a cadeia das hipóteses causais estabelecendo um vínculo entre os recursos, os resultados intermediários das atividades e os objetivos últimos do programa.

Na década de 90, $\operatorname{Chen}^{17}$ (1990) atribuiu à modelização um poder analítico, além de seu valor descritivo: para ele, o modelo lógico tinha por objeto não apenas os objetivos, mas também os efeitos e consequências possíveis da intervenção. No mesmo ano, Jean-Louis Le Moigne ${ }^{18}$ conceituou a modelização: "a ação de elaboração e construção intencional, por composição de símbolos, de modelos suscetíveis de tornar inteligível um fenômeno perceptivelmente complexo, que amplia o raciocínio do ator que projeta uma intervenção deliberada no cerne do fenômeno, raciocínio que tem por objetivo em especial antecipar as consequências desses projetos de ações possíveis".

\section{CÂNCER COLORRETAL}

No mundo, o câncer colorretal é a terceiro tipo de câncer mais prevalente, sendo estimados mais de 1,2 milhões de casos novos e mais de 600.000 óbitos por $a^{19}{ }^{19}$. No Brasil, segundo dados do Instituto Nacional de Câncer José Alencar Gomes da Silva, a estimativa para o ano de 2014, válida também para o ano de 2015, apontou para a ocorrência de aproximadamente 
33 mil casos novos de câncer colorretal. No Estado de São Paulo, foram estimados aproximadamente 11,5 mil casos novos em 2015 . No ICESP, dados do Registro Hospitalar de Câncer apontaram como os mais prevalentes em ordem de frequência: câncer de próstata, mama e tumores colorretais.

Dentre os tumores colorretais, o câncer de reto representa aproximadamente $25 \%$ de todos os cânceres primários. Os fatores de risco associados às neoplasias colorretais são idade, sexo masculino, pólipos colônicos, história individual e/ou familiar de câncer colorretal e fatores ambientais, como dieta rica em carne vermelha e gorduras e pobre em frutas e verduras; obesidade; tabagismo; sedentarismo e diabetes mellitus ${ }^{20-24}$. Doença inflamatória intestinal e história pregressa de radioterapia para tratamento de neoplasia de próstata também são considerados fatores de risco ${ }^{24,25}$.

Nas últimas décadas houve a integração entre as diversas modalidades terapêuticas para o tratamento do câncer de reto, com o apuramento de técnicas operatórias, novas tecnologias radioterápicas e drogas quimioterápicas mais eficazes ${ }^{24}$. Nas décadas de 70 e 80 , sedimentaram-se duas correntes para o tratamento complementar à cirurgia: a da neoadjuvância, praticada pela escola europeia, e a da adjuvância, pela escola americana ${ }^{26,27}$. Heald, no início da década de 80, mostrou a importância da excisão total do mesorreto no controle da recidiva local após a cirurgia do câncer de reto ${ }^{28,29}$, e desde então, esta é a técnica operatória preconizada.

A excisão total do mesorreto consiste na retirada de todo o tecido gorduroso perirretal através de dissecção do reto no plano situado entre sua 
fáscia própria e sua fáscia parietal, junto às paredes pélvicas, até o plano dos músculos elevadores, no caso de tumores de reto médio e distal.

A via de acesso da cirurgia pode ser laparoscópica ou por laparotomia. O cirurgião executa a excisão total do mesorreto, obtém margens de segurança laterais e preserva os nervos hipogástricos superiores e inferiores, desde a região de dissecção da artéria mesentérica inferior até a intimidade da escavação pélvica, com o objetivo de reduzir os índices de bexiga neurogênica e distúrbios sexuais. Dependendo da técnica utilizada, do tamanho e da localização do tumor, é possível a preservação esfincteriana. No caso de aderências do tumor a estruturas e órgãos vizinhos, a técnica varia de uma ressecção simples em monobloco da parede posterior da vagina a uma exenteração pélvica completa ${ }^{24}$.

A neoadjuvância tem sido indicada para tumores localizados em reto baixo e médio, que infiltram até a subserosa ou gordura perirretal, ou que invadem outros órgãos ou estruturas, classificados como T3 e T4 segundo o sistema de estadiamento $\mathrm{T}$ : tumor, $\mathrm{N}$ : linfonodo, $\mathrm{M}$ : metástase. Para tumores que infiltram a submucosa ou a muscular própria, classificados como T1 e T2, a neoadjuvância é indicada quando existe envolvimento linfonodal peritumoral ou quando se pretende realizar cirurgia de ressecção local. O racional para o tratamento neoadjuvante do câncer de reto com radioterapia associada à quimioterapia fundamenta-se nos seguintes aspectos: possibilidade de redução tumoral, favorecendo a completa ressecção do tumor; aumento da possibilidade de se realizar cirurgia com preservação esfincteriana; oportunidade de melhor definição do alvo do tratamento radioterápico e menor 
irradiação de tecidos normais em relação ao tratamento pós-operatório; chance de se testar a interação de novas drogas pela avaliação da resposta patológica após a cirurgia; informação prognóstica relacionada com a intensidade de resposta ${ }^{24}$.

O sucesso no manejo do câncer de reto requer uma abordagem multidisciplinar ${ }^{30,31,32}$, incluindo cirurgiões do aparelho digestivo, oncologistas clínicos, radioterapeutas, endoscopistas, radiologistas e patologistas ${ }^{33}$.

O Instituto do Câncer do Estado de São Paulo (ICESP) foi inaugurado em maio de 2008, inicialmente como organização social de saúde, através de parceria entre a Fundação Faculdade de Medicina e a Secretaria de Estado da Saúde de São Paulo. Desde novembro de 2013, faz parte da Autarquia Especial do Hospital das Clínicas da Faculdade de Medicina da Universidade de São Paulo. O ICESP foi concebido como centro de excelência na área do câncer, dispondo de todos os recursos necessários para o atendimento oncológico: recursos humanos (médicos e equipe multiprofissional capacitada e especializada), recursos tecnológicos (equipamentos de diagnóstico por imagem, medicina nuclear, aceleradores lineares, equipamentos endoscópicos e cirurgia por vídeo), estrutura física (ambulatórios, unidade de internação, centro cirúrgico, pronto socorro, unidade de terapia intensiva), tecnologia de informação (prontuário eletrônico, sistema de armazenamento de imagens, sistema de gerenciamento de radioterapia) e estrutura administrativa e de apoio.

Rapidamente tornou-se referência no cuidado oncológico no Estado de São Paulo, com números crescentes de atendimento, atingindo 6.428 
pacientes atendidos em dez 2008, 16.163 em 2009, 22.706 em 2010, 27.669 em 2011; completou o ano de 2014 com 38.580 pacientes atendidos.

No ICESP, os protocolos de conduta oncológica foram discutidos com os membros da Faculdade de Medicina da Universidade de São Paulo e membros do corpo clínico do Instituto, e posteriormente com a Secretaria de Estado da Saúde de São Paulo, e disponibilizadas em Manual de Condutas em Oncologia $^{34,35}$ e Manual de condutas em Oncologia Cirúrgica ${ }^{36}$. O tratamento padrão neoadjuvante preconizado para neoplasias de reto médio e baixo, localmente avançadas, consistia em radioterapia de 5040 cGy distribuídas em 28 frações durante cinco semanas de tratamento, com quimioterapia concomitante por dois ciclos de cinco dias, durante as semanas um e cinco de radioterapia. A cirurgia, após o tratamento neoadjuvante, seria realizada com excisão total do mesorreto.

Apesar das diretrizes publicadas, conhecidas e disponibilizadas a todo 0 corpo clínico; de recursos humanos, estruturais e tecnológicos existentes, havia indícios de dificuldades no encaminhamento entre as equipes assistenciais, tempos prolongados para liberação de laudos de exames subsidiários e dificuldades de agendamento de radioterapia e cirurgia. Era necessário gerenciar, de forma coordenada, os recursos disponíveis, na sequência e em prazos adequados para as condutas definidas.

Em março de 2011, por iniciativa da Diretoria Clínica, todas as áreas médicas envolvidas no tratamento dos pacientes com tumores de reto (oncologia clínica, cirurgia do aparelho digestivo, radioterapia, endoscopia, anestesia, clínica médica, diagnóstico por imagem e patologia) revisaram o protocolo institucional de tratamento neoadjuvante para adenocarcinoma de 
reto, e estabeleceram a sequência das etapas, com prazos e intervalos desejáveis. Este protocolo foi nomeado de Fluxo Gerenciado FGC20 (FGC20), uma intervenção classificada como tecnologia de processo.

Para a sua implantação, as áreas administrativa e multiprofissional desenvolveram soluções para viabilizar as marcações de consultas, exames, quimioterapia, radioterapia e cirurgia conforme os intervalos previamente definidos. O FGC20 iniciou em 12 de maio de 2011.

Pretende-se, através deste estudo, identificar as melhorias, as dificuldades, os fatores críticos de sucesso no período de implantação e avaliar os impactos em relação aos recursos utilizados e à dinâmica do cuidado, na perspectiva do ICESP. 


\section{OBJETIVOS}




\section{OBJETIVOS}

\section{Objetivo Geral}

O objetivo geral deste estudo é avaliar a implantação do modelo de gerenciamento do protocolo clínico institucional para o tratamento neoadjuvante do adenocarcinoma de reto, nomeado Fluxo Gerenciado FGC20, adotado no ICESP.

\section{Objetivos Específicos}

1. Construir o modelo lógico do FGC20

2. Avaliar intervalos de tempos entre as etapas do tratamento de pacientes do FGC20 e do controle histórico

3. Mensurar os recursos utilizados e descrever os custos do tratamento dos pacientes no período prévio ao FGC20 e na vigência do FGC20

4. Verificar a sobrevida global dos pacientes tratados no período prévio ao FGC20 e na vigência do FGC20 
MÉTODOS 


\section{MÉTODOS}

\subsection{CONTEXTO}

\section{SITUAÇÃO INICIAL: O PERÍODO PRÉVIO À IMPLANTAÇÃO}

O período prévio à implantação do FGC20 (PRÉ FLUXO) correspondeu ao intervalo entre 06 de maio de 2008, data de inauguração do ICESP, a 11 de maio de 2011. O processo de admissão de pacientes era desencadeado pelo recebimento de solicitação médica enviada por equipamentos de saúde da Secretaria de Saúde do Estado de São Paulo. Realizava-se a avaliação documental administrativa, e na sequência, a triagem documental pela equipe médica da oncologia clínica ou da cirurgia do aparelho digestivo, aceitando ou não o encaminhamento do paciente.

A triagem documental era feita pela oncologia clínica, quando havia a citação de necessidade de quimioterapia, ou relato de cirurgia realizada previamente. A cirurgia do aparelho digestivo realizava a triagem documental quando não havia relato de tratamento prévio. Após o aceite por uma das especialidades, a consulta médica era agendada. No decorrer do atendimento ambulatorial, eram solicitados exames subsidiários para o estadiamento, segundo critérios de cada especialidade, a qual encaminhava a outras especialidades médicas e multiprofissionais quando necessário ou após a finalização de sua etapa no tratamento do paciente. Não havia definição de prazos para o cumprimento das etapas do plano terapêutico e os protocolos de 
tratamento já estavam estabelecidos. Até 2010, a radioterapia neoadjuvante era realizada no Instituto de Radiologia do Hospital das Clínicas da Faculdade de Medicina da Universidade de São Paulo (InRad), e após a inauguração dos aceleradores lineares, passou a ser feita no ICESP.

\section{A INTERVENÇÃO: O FGC20}

Mediado pela Diretoria Clínica do ICESP, as equipes médicas da oncologia clínica, cirurgia do aparelho digestivo, radioterapia, diagnóstico por imagem, patologia, endoscopia, anestesia e clínica médica revisaram o protocolo institucional de tratamento neoadjuvante do câncer de reto baixo e médio. Propuseram como tempo ideal o intervalo de 15 dias entre 0 encaminhamento do paciente até a marcação da primeira consulta, com as especialidades oncologia clínica ou cirurgia do aparelho digestivo.

Em conjunto, definiram os exames para estadiamento: exames laboratoriais, radiografia de tórax (RX tórax), tomografia computadorizada (TC) de abdome, ressonância magnética ( $\mathrm{RM}$ ) de pelve e colonoscopia/retoscopia com biópsia. A consulta de retorno do paciente, para confirmação da proposta de tratamento neoadjuvante seria realizada no período de 15 dias após a primeira consulta médica.

Na sequência, o paciente seria encaminhado para iniciar o tratamento neoadjuvante, com quimioterapia e radioterapia concomitantes, consistindo em dose total de radioterapia de 5040 cGy, distribuídas em 28 frações diárias, concomitante à quimioterapia com ácido folínico $\left(20 \mathrm{mg} / \mathrm{m}^{2}\right.$, IV, bolus D1a D5) 
e 5-fluorouracil ( $350 \mathrm{mg} / \mathrm{m}^{2}, \mathrm{IV}$, bolus D1 a D5), durante as semanas um e cinco da radioterapia ${ }^{37}$.

Dois meses após o final do tratamento neoadjuvante, o paciente seria submetido a reestadiamento, com repetição dos exames laboratoriais, $\mathrm{RX}$ tórax, TC de abdome, RM de pelve e colonoscopia/retoscopia. A cirurgia seria feita no prazo de 30 dias a partir da realização de todos os exames.

O intervalo de tempo entre o final do tratamento neoadjuvante e a cirurgia totalizaria 12 semanas. O período total de tratamento, desde a primeira consulta até a cirurgia seria de 25 semanas.

Para identificar os pacientes inseridos no FGC20, foi criado um alerta no prontuário eletrônico do paciente, visível a todos os usuários, denominado Flag.

O FGC20 iniciou no dia 12 de maio de 2011. A sequência das etapas está representada no diagrama da figura 1 : 
Figura 1: Diagrama do Fluxo Gerenciado FGC20, ICESP,2011

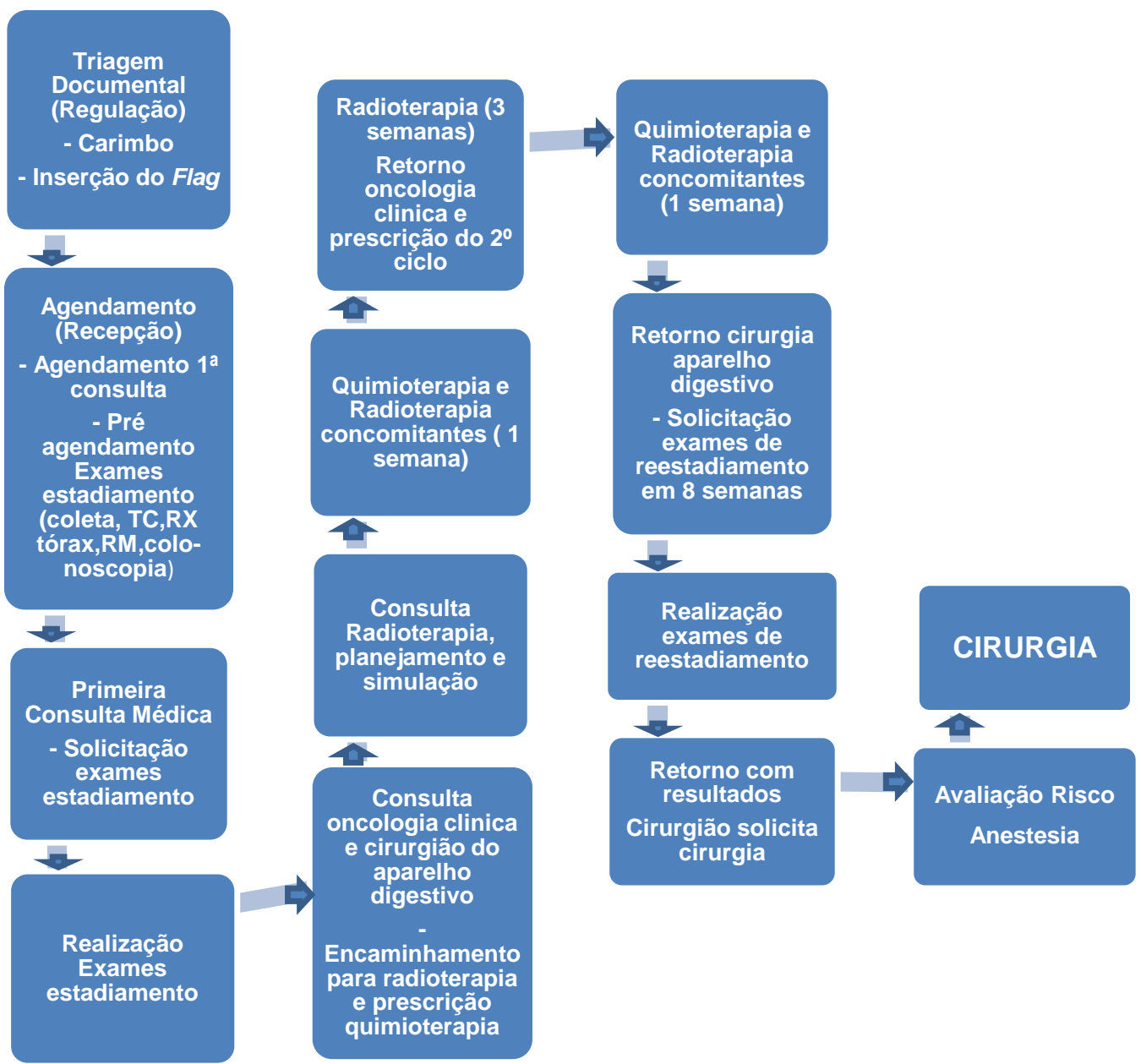

Flag - alerta no prontuário eletrônico identificando o paciente como pertencente ao Fluxo Gerenciado FGC20 TC - Tomografia computadorizada RX tórax - Radiografia de tórax

RM - Ressonância magnética 


\subsection{CONSTRUÇÃO DO MODELO LÓGICO}

A modelização da intervenção FGC20 foi utilizada para descrição do processo de implantação, concebendo-a como um sistema organizado de ações, relacionando os seguintes componentes, em quatro divisões: os atores (os agentes envolvidos nas diversas atividades), o objetivo (o estado futuro para o qual o processo de ação é orientado), as atividades (o conjunto de ações desenvolvidas pelos atores) e os resultados (o produto gerado pelas atividades realizadas).

Foi construído um modelo lógico operacional, em forma de diagrama, correlacionando todas as atividades realizadas no processo de implantação do FGC20 a objetivos específicos que viabilizaram o desenvolvimento da intervenção, explicitando os principais envolvidos e os resultados esperados. A elaboração foi feita com base na informação obtida com perguntas: "Quem faz?", "Quais os recursos necessários?", "Quais atividades previstas?" e "Qual o resultado esperado?".

A partir do modelo lógico, foram identificados indicadores de monitoramento do processo de implantação. Estes indicadores foram selecionados por serem mensuráveis e terem sido definidos no fluxograma do FGC20. A medida do indicador foi demonstrada como a proporção de pacientes que atingiram a meta estabelecida. 


\subsection{GRUPOS PRÉ FLUXO E FGC20}

Além dos indicadores de monitoramento da implantação do FGC20, foi selecionado um controle histórico para comparar o FGC20 e o período prévio a sua implantação. Pacientes com diagnóstico de neoplasia maligna do reto baixo e médio, admitidos no ICESP, no período de 06/05/2008 a 31/12/2013, foram observados, retrospectivamente, considerando 2 grupos:

a) grupo PRÉ FLUXO: pacientes cuja entrada ocorreu entre 06/05/2008, data da inauguração do instituto, até o dia 11/05/2011, considerado o grupo controle;

b) grupo FGC20: pacientes com início de atendimento entre 12/05/2011, data de início do FGC20, até 31/12/2013, considerado o grupo experimental.

Os critérios de inclusão foram:

- pacientes com o diagnóstico de câncer de reto;

- pacientes tratados com quimioterapia e radioterapia concomitantes e posterior realização de cirurgia.

Os critérios de exclusão foram:

- pacientes metastáticos ao diagnóstico inicial;

- pacientes sem indicação do protocolo de tratamento neoadjuvante preconizado, por indicação de cirurgia imediata ou por indicação clínica de radioterapia neoadjuvante de curso rápido; 
- pacientes que não realizaram o tratamento neoadjuvante por falta de condições clínicas;

- pacientes com tratamento de quimioterapia, radioterapia ou cirurgia, prévios ao início de tratamento no ICESP;

- recusa ou má aderência do paciente ao tratamento neoadjuvante. 


\subsection{MENSURAÇÃO DOS INTERVALOS DE TEMPO}

De ambos os grupos, PRÉ FLUXO e FGC20, foram obtidas as seguintes informações: data da primeira consulta médica, data do início e término da quimioterapia e radioterapia neoadjuvantes (nCRT) e data da cirurgia. A data da inserção do Flag foi obtida para o grupo FGC20.

A coleta das datas de alertas, consultas e cirurgia foi feita a partir de planilhas disponibilizadas pelo setor de Gestão da Informação em Saúde, obtidas do sistema de gestão em saúde Philips Tasy® (Philips Clinical Informatics, Blumenau, Brasil). As informações sobre a radioterapia foram obtidas a partir do sistema informatizado Mosaiq ${ }^{\circledR}$ (Elekta $A B$, Estocolmo, Suécia). Foram definidos os seguintes intervalos de tempo:

- intervalo entre inserção do Flag e realização da primeira consulta (apenas para o grupo FGC20);

- intervalo entre primeira consulta e início da nCRT;

- intervalo entre início e término da nCRT;

- intervalo entre final da nCRT e cirurgia;

- intervalo entre primeira consulta e cirurgia. 


\subsection{MENSURAÇÃO DOS RECURSOS, CUSTOS E SOBREVIDA}

O horizonte temporal da coleta de recursos utilizados foi o intervalo entre a data da primeira consulta médica até 30 dias após a realização da cirurgia, em ambos os grupos. Este intervalo foi definido por conter todas as etapas previstas no FGC20: consultas, estadiamento, radioterapia, quimioterapia e cirurgia. O período de 30 dias após a realização da cirurgia foi definido pelas equipes médicas por abranger possíveis complicações no pós operatório da cirurgia.

Foram utilizadas planilhas disponibilizadas pelo setor de Gestão da Informação em Saúde, obtidas do sistema de gestão em saúde Philips Tasy®, contendo as informações: registro do paciente no hospital; 10ª edição da Classificação Estatística Internacional de Doenças e Problemas Relacionados com a Saúde (CID); datas de consultas das especialidades médicas e multiprofissionais; datas de coleta de exames laboratoriais; data da inserção do alerta FGC20; setores de internação e seus respectivos períodos de admissão e alta; data e nome das cirurgias realizadas e protocolos de quimioterapia realizados.

Dados da radioterapia foram extraídos do sistema informatizado de radioterapia Mosaiq ${ }^{\circledR}$, contendo datas, sessões e check films realizados. Para alguns pacientes da coorte PRÉ FLUXO, os dados foram obtidos a partir da visualização de prontuário e ficha técnica do InRad, digitalizados no sistema de

digitalização de documentos Laserfiche ${ }^{\circledR}$ (Laserfiche Run Smarter, Long 
Beach, Califórnia, Estados Unidos) que permite a visualização de documentos digitalizados no prontuário eletrônico do paciente do sistema Tasy®.

O quantitativo de colonoscopias/retoscopias, TC e RM foi obtido através de relatórios dos sistemas informatizados de gerenciamento de imagens Philips XIRIS® e MultiMED® (Philips Medical Systems, Best, Holanda).

Dados referentes ao diagnóstico inicial foram obtidos a partir da visualização de exames anátomo-patológicos de admissão do paciente no ICESP, em formulários digitalizados no sistema Laserfiche ${ }^{\circledR}$, pesquisa de laudos em sistema HCMED® (Hospital das Clínicas da Universidade de São Paulo, São Paulo, Brasil) ou dados disponibilizados pelo Registro Hospitalar de Câncer. Dados referentes ao último atendimento no hospital e/ou óbito foram obtidos a partir da verificação direta em prontuário eletrônico do paciente ou informações disponibilizadas pelo Registro Hospitalar de Câncer.

Para o grupo FGC20, foi utilizada a planilha Excel(C administrativa, de controle e monitoramento ativo de pacientes do FGC20, compartilhada em servidor departamental, denominada "Pacientes ativos; completa-realizadaóbito".

Foi construído um Banco de Dados individuais dos pacientes em planilha Excel@, utilizando informações extraídas do sistema de gestão em saúde Philips Tasy ${ }^{\circledR}$, sistema de digitalização de documentos Laserfiche ${ }^{\circledR}$, sistema informatizado de radioterapia Mosaiq ${ }^{\circledR}$, sistemas informatizados de gerenciamento de imagens Philips XIRIS $\AA$ e MultiMED $\AA$, sistema HCMED $\AA$ e dados do Registro Hospitalar de Câncer, contendo as informações abaixo. 
- Registro do paciente no hospital.

- Data de nascimento.

- Sexo.

- Data da inserção do Flag.

- Data da primeira consulta médica.

- Número de consultas com oncologista clínico, da primeira consulta médica até 30 dias após a cirurgia.

- Número de consultas com cirurgião do aparelho digestivo, da primeira consulta médica até 30 dias após a cirurgia.

- Número de consultas com clínico, para avaliação de risco cirúrgico, da primeira consulta médica até 30 dias após a cirurgia.

- Número de consultas com anestesista, da primeira consulta médica até 30 dias após a cirurgia.

- Número de consultas com radioterapeuta, da primeira consulta médica até 30 dias após a cirurgia.

- Número de consultas da equipe multiprofissional: enfermagem, nutricionista, fisioterapeuta, assistente social, psicologia, da primeira consulta médica até 30 dias após a cirurgia.

- Número de consultas médicas de outras especialidades cirúrgicas e clínicas, exceto oncologistas, cirurgião do aparelho digestivo, avaliação de risco e anestesista, da primeira consulta médica até 30 dias após a cirurgia.

- Número de consultas de odontologistas, da primeira consulta médica até 30 dias após a cirurgia. 
- Número de atendimentos em hospital dia e ambulatório de infusão terapêutica, da primeira consulta médica até 30 dias após a cirurgia.

- Número de coletas externas de exames laboratoriais, da primeira consulta médica até 30 dias após a cirurgia.

- Número de TC realizadas, da primeira consulta médica até 30 dias após a cirurgia.

- Número de RM realizadas, da primeira consulta médica até 30 dias após a cirurgia.

- Número de colonoscopias/retoscopias realizadas, da primeira consulta médica da primeira consulta médica até 30 dias após a cirurgia.

- Protocolo de quimioterapia de indução.

- Protocolo de quimioterapia neoadjuvante concomitante à radioterapia.

- Data de início da radioterapia neoadjuvante.

- Data de término da radioterapia neoadjuvante.

- Número de sessões de radioterapia.

- Número de check films realizados.

- Data e nome da cirurgia principal.

- Número, data e hora de atendimentos no Centro de Atendimento às Intercorrências Oncológicas (CAIO), da primeira consulta médica até 30 dias após a cirurgia. 
- Número de dias de internação no CAIO, da primeira consulta médica até 30 dias após a cirurgia.

- Número de dias de internação em unidade de internação (UI), da primeira consulta médica até 30 dias após a cirurgia.

- Número de dias de internação em unidade de terapia intensiva (UTI), da primeira consulta médica até 30 dias após a cirurgia.

- Data do diagnóstico do tumor.

- Estádio clínico inicial, conforme 6a edição do Sistema de estadiamento: T-tumor, $\mathrm{N}$-linfonodo, M-metástase (TNM), American Joint Committee on Cancer (AJCC).

- Estádio patológico, conforme 6ª edição do TNM, AJCC.

- Data do último atendimento no hospital.

- Data do óbito.

\section{Método de Custeio}

A descrição de custos diretos médicos do tratamento foi feita na perspectiva do serviço - o ICESP, com a metodologia mista de custeio, com microcusteio para o cômputo individual de consultas, exames de imagem e sessões de radioterapia e quimioterapia, e macrocusteio para o cálculo de custo dos valores de internação e cirurgia. Os custos estão apresentados em Reais de 2015.

Para a valoração dos custos foi utilizada a tabela de custos do ICESP, com valores de referência de janeiro a julho de 2015, cuja apuração utiliza a 
metodologia de custeio por absorção, considerando os custos fixos, variáveis e rateios dos recursos humanos, recursos materiais e infraestrutura para 0 cálculo do valor unitário de consulta médica, consulta multiprofissional, consulta de odontólogo, TC, RM, colonoscopia/retoscopia, sessão de radioterapia, diária de UI, diária de UTI e diária de hospital dia.

Para os eventos atendidos na unidade de urgência e emergência - CAIO - considerou-se o valor proporcional da média de tempo de atendimento dos eventos dos grupos PRÉ FLUXO e FGC20 no CAIO, em relação ao valor de uma diária nesta unidade.

O custo médio da quimioterapia foi calculado no mês de referência junho 2015, considerando superfície corpórea média de $1,8 \mathrm{~m}^{2}$, e materiais e medicamentos conforme padronização do serviço ${ }^{35,36}$. No cálculo do protocolo FULV considerou-se ácido folínico $\left(20 \mathrm{mg} / \mathrm{m}^{2}\right.$, IV, bolus D1a D5) e 5fluorouracil (350 mg/m², IV, bolus D1 a D5), durante as semanas um e cinco da radioterapia. Para o cálculo do protocolo mFLOX considerou-se oxaliplatina (85 $\mathrm{mg} / \mathrm{m}^{2} \mathrm{IV} 2$ horas, semanas 1,3,5), ácido folínico (20 mg/ $\mathrm{m}^{2} \mathrm{IV}$ bolus, semanas 1,2,3,4,5,6) e 5-fluorouracil $\left(500 \mathrm{mg} / \mathrm{m}^{2}\right.$ IV bolus, semanas $1,2,3,4,5,6)$.

O custo médio das cirurgias foi calculado a partir do valor unitário do minuto cirúrgico (referência: média de janeiro a julho 2015) e medianas de tempos dos procedimentos de retossigmoidectomia aberta, retossigmoidectomia por videolaparoscopia e amputação de reto. Adotou-se, para as cirurgias de enxenteração pélvica e laparotomia exploradora a mediana de tempo da cirurgia de amputação de reto. O valor unitário do minuto cirúrgico 
considera o valor do centro cirúrgico de custos fixos, variáveis e rateios em recursos humanos, materiais, medicamentos, infraestrutura e exames realizados. 


\subsection{ANÁLISE ESTATÍSTICA}

A análise estatística utilizou o software estatístico SPSS for Windows v.18.0 (SPSS Inc., Chicago, IL, Estados Unidos).

As variáveis qualitativas foram apresentadas por frequências e porcentagens. As variáveis quantitativas foram apresentadas pela média, mediana, desvio padrão e valores mínimo e máximo.

A associação entre as variáveis demográficas, clínicas, patológicas e utilização de recursos segundo as coortes observadas (PRÉ FLUXO e FGC20) foi analisada pelo teste qui-quadrado de Pearson ou teste exato de Fisher para as variáveis qualitativas; para as variáveis quantitativas utilizou-se o teste t de Student ou teste Mann-Whitney. As curvas de sobrevida global foram calculadas segundo o método de Kaplan-Meier e comparadas utilizando o teste log-rank.

O nível de significância adotado para todos os testes estatísticos foi de $5 \%$. 


\subsection{ASPECTOS ÉTICOS}

Este estudo foi aprovado pelo Comitê de Ética em Pesquisa da Faculdade de Medicina da Universidade de São Paulo em 07/05/2014, sob o nำ126/14. 
RESULTADOS 


\section{RESULTADOS}

\subsection{MODELO LÓGICO DO FGC20}

O modelo lógico da implantação do FGC20 (figura 2) esquematiza as atividades desenvolvidas e as correlaciona aos agentes, aos objetivos e aos resultados esperados. 
Figura 2. Modelo lógico da implantação do Fluxo Gerenciado FGC20, ICESP 2011

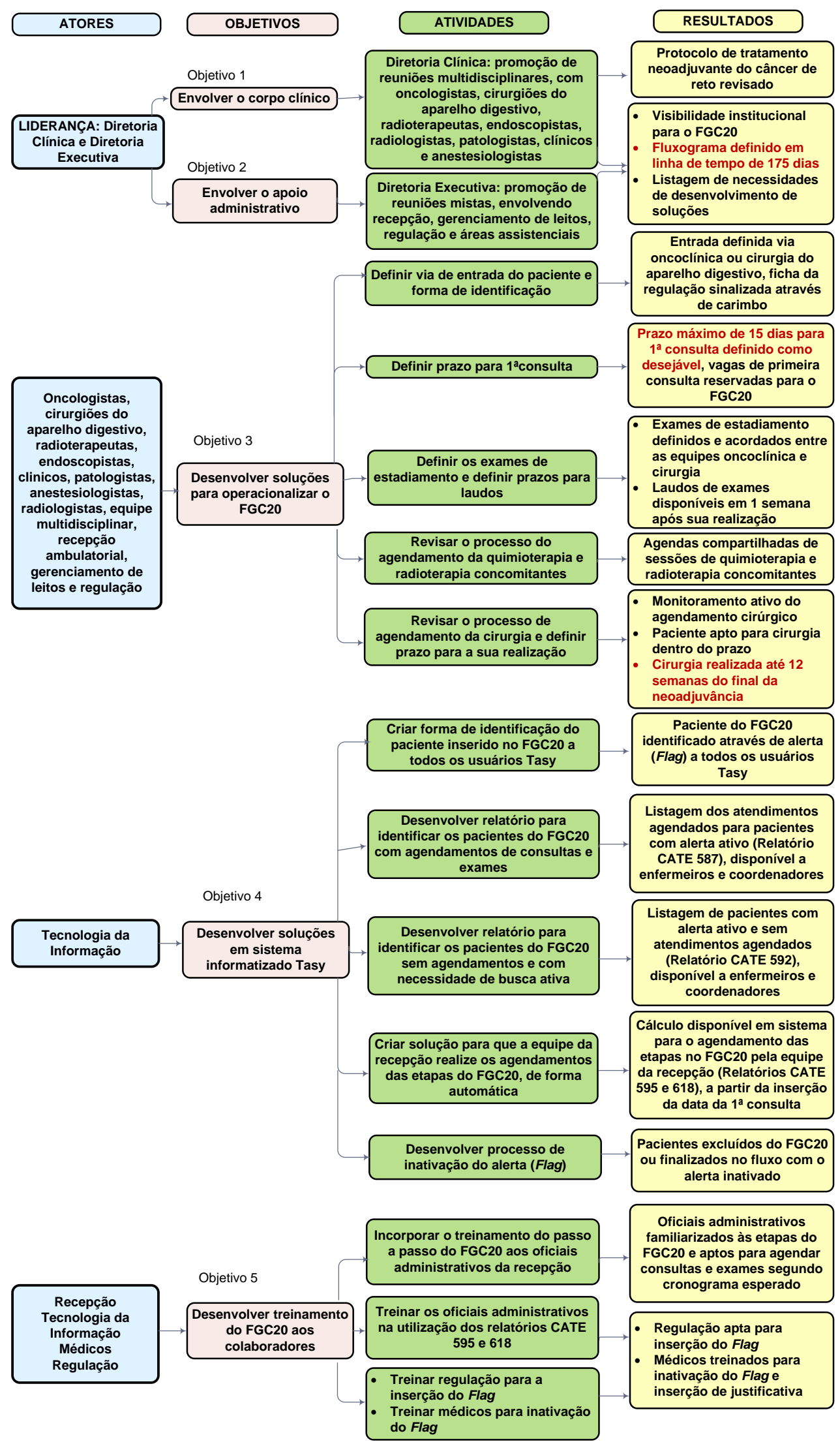

FGC20: fluxo gerenciado FGC20 Flag: alerta no prontuário eletrônico identificando o paciente como pertencente ao FGC20 CATE: relatórios desenvolvidos pelo cliente, C:cliente, ATE: atendimento 


\section{Objetivo 1- Envolver o corpo clínico}

Para a implantação do FGC20, o marco inicial das atividades foi o envolvimento do corpo clínico. Foram realizadas reuniões multidisciplinares, sob a liderança da Diretoria Clínica, com a participação das equipes médicas envolvidas nas etapas de tratamento do paciente com câncer de reto: oncologistas, cirurgiões do aparelho digestivo, radioterapeutas, endoscopistas, radiologistas, patologistas, clínicos e anestesiologistas. Em conjunto, revisaram o protocolo de tratamento neoadjuvante do câncer de reto, e a Diretoria Clínica imprimiu um caráter institucional à proposta do FGC20.

\section{Objetivo 2- Envolver o apoio administrativo}

Após a revisão do protocolo, a Diretoria Executiva mobilizou o grupo de apoio administrativo para o desenho do fluxograma do FGC20, com a participação das áreas de recepção ambulatorial, gerenciamento de leitos e agenda cirúrgica, regulação (responsável pela entrada de pacientes novos no ICESP) e equipes assistenciais (médicas e multiprofissionais). As equipes definiram o fluxograma (figura 1) e levantaram os pontos críticos e necessidades de desenvolvimento de soluções.

\section{Objetivo 3- Desenvolver soluções para operacionalizar o FGC20}

Para a operacionalização do FGC20, o primeiro ponto crítico mapeado no fluxograma foi a definição e identificação da via de entrada do paciente no 
FGC20. Oncologistas, cirurgiões do aparelho digestivo e o setor regulação estabeleceram a entrada de pacientes no FGC20 através de triagem documental tanto pela oncologia clínica quanto pela cirurgia do aparelho digestivo, e a sinalização de inclusão no FGC20 através de um carimbo na ficha da triagem documental, possibilitando a identificação do paciente pelo setor regulação.

O segundo ponto crítico identificado pelas equipes foi a necessidade de garantir vagas de primeira consulta para o paciente do FGC20. O setor de recepção ambulatorial e equipes médicas definiram o prazo de 15 dias entre o aceite da triagem e a realização da primeira consulta e estabeleceram, nas agendas médicas, vagas reservadas de primeira consulta para pacientes do FGC20.

O terceiro ponto crítico foi a diversidade de exames de apoio diagnóstico solicitados e prazos variáveis de laudos. Oncologistas e cirurgiões definiram tipos e quantidades de exames laboratoriais, exames de imagem e colonoscopias/retoscopias para as fases de estadiamento e reestadiamento. Em conjunto com radiologistas, patologistas, endoscopistas e recepção, definiram um intervalo desejável de 15 dias entre a realização dos exames e o retorno médico.

O quarto ponto crítico identificado foi a necessidade de garantir os agendamentos concomitantes entre os setores de quimioterapia e radioterapia na primeira e quinta semanas da nCRT, e prezar pelo agendamento de radioterapia na segunda, terceira e quarta semanas desta etapa do tratamento. As equipes da radioterapia, quimioterapia, equipe multidisciplinar e recepções 
desenvolveram uma planilha compartilhada para a marcação das sessões de quimioterapia e radioterapia para assegurar a visualização mútua e em tempo real de ambos os setores.

O quinto ponto crítico identificado pelas equipes foi a necessidade de garantir o prazo para realizar a cirurgia após o tratamento neoadjuvante. $\mathrm{O}$ setor de Gerenciamento de Leitos e Agenda Cirúrgica desenvolveu uma planilha no servidor departamental, nomeada "Pacientes ativos; completarealizada-óbito" contendo a informação da data de início e término da nCRT, datas esperada e realizada para a confecção do pedido de agendamento cirúrgico, datas esperada e realizada de avaliação anestésica e datas esperada e realizada da cirurgia. O objetivo da planilha foi monitorar e convocar ativamente os pacientes do FGC20, através da verificação da confecção do pedido de cirurgia, avaliação de risco cirúrgico e agendamento cirúrgico em relação ao período ideal de realização, de forma a cumprir, dentro do prazo, a última etapa do FGC20 - a cirurgia.

\section{Objetivo 4- Desenvolver soluções em sistema informatizado Tasy®}

O setor de Tecnologia de Informação desenvolveu soluções no sistema informatizado Tasy ${ }^{\circledR}$ para a implantação do FGC20.

O alerta no prontuário eletrônico do paciente, denominado Flag, foi criado para permitir que as equipes, tanto assistenciais quanto administrativas, identificassem o paciente pertencente ao FGC20. Ao acessar o sistema Tasy® com o registro de paciente do FGC20, automaticamente o alerta contendo a 
informação: "Paciente pertencente ao Fluxo Gerenciado FGC20" apareceria na primeira tela do sistema. Por consenso, foi decidido que o setor regulação seria o responsável pela inserção do Flag.

Relatórios foram desenvolvidos pela equipe de tecnologia de informação do ICESP (relatórios CATE - C: cliente, ATE: atendimento). O relatório CATE 587 foi desenvolvido para que enfermeiros e coordenadores pudessem visualizar os atendimentos agendados para pacientes com Flag ativo, facilitando a verificação dos pacientes do FGC20 dentre a totalidade de pacientes atendidos no ICESP.

O relatório CATE 592 foi criado para permitir a visualização de pacientes com o alerta ativo, porém sem atendimentos agendados, facilitando a busca ativa do paciente não agendado.

A solução para que a equipe de recepção pudesse realizar agendamento das etapas do FGC20, sem a necessidade de memorizar passos e prazos do protocolo foi o desenvolvimento dos relatórios CATE 595 e 618. Estes relatórios calculavam e listavam as datas necessárias para o pré agendamento do paciente, a partir da inserção da data da primeira consulta, segundo o cronograma do protocolo e os dias de agendas disponíveis.

Foi necessário desenvolver um processo de inativação do alerta para que médicos ou setor regulação pudessem excluir ou finalizar o paciente no FGC20. Foi definida a obrigatoriedade de anotação do motivo de inativação para finalização do processo. 


\section{Objetivo 5- Desenvolver treinamento do FGC20 aos colaboradores}

Foi definido um treinamento sistemático do setor recepção para apresentar o passo a passo do FGC20 aos oficiais administrativos da recepção. O treinamento também englobava a capacitação para utilizar os relatórios CATE 595 e 618, visando assegurar o agendamento de consultas e exames segundo o cronograma esperado. O setor regulação recebeu treinamento para a inserção do Flag em pacientes elegíveis ao FGC20, identificados pelas equipes médicas a partir da triagem documental de pacientes encaminhados ao ICESP.

O setor de Tecnologia da Informação do ICESP desenvolveu um manual de treinamento de inativação do Flag. O manual foi apresentado em reuniões médicas e disponibilizado por correio eletrônico aos médicos da oncologia clínica e cirurgiões do aparelho digestivo. 


\subsection{AVALIAÇÃO DOS INTERVALOS DE TEMPO E INDICADORES DE MONITORAMENTO DE RESULTADOS DO MODELO LÓGICO}

624 pacientes com diagnóstico de câncer de reto foram matriculados no ICESP, no período de 06/05/2008 a 31/12/2013 (figura 3).

O grupo PRÉ FLUXO, entre 06/05/2008 a 11/05/2011, incluiu 211 pacientes. Destes, 99 pacientes foram excluídos: 28 por se apresentarem metastáticos ao diagnóstico inicial, 29 por não terem indicação de tratamento neoadjuvante pela equipe médica, 12 por não realizarem tratamento neoadjuvante por falta de condições clínicas, 29 por tratamentos prévios realizados e 1 por recusa e/ou má aderência ao tratamento neoadjuvante (figura 3).

O grupo FGC20 foi composto por pacientes admitidos entre 12/05/2011, data de início do FGC20, até 31/12/2013, totalizando 413 pacientes. 195 pacientes foram excluídos pelas seguintes constatações: 74 metastáticos ao diagnóstico inicial, 64 por não terem indicação de tratamento neoadjuvante pela equipe médica, 28 por não realizarem o tratamento neoadjuvante por falta de condições clinicas, 21 por tratamentos prévios realizados e 8 por recusa e/ou má aderência ao tratamento neoadjuvante (figura 3).

330 pacientes foram analisados, sendo 112 do grupo PRÉ FLUXO e 218 do grupo FGC20 (figura 3). 
Figura 3: Descritivo de pacientes com câncer de reto observados 2008-2013, ICESP

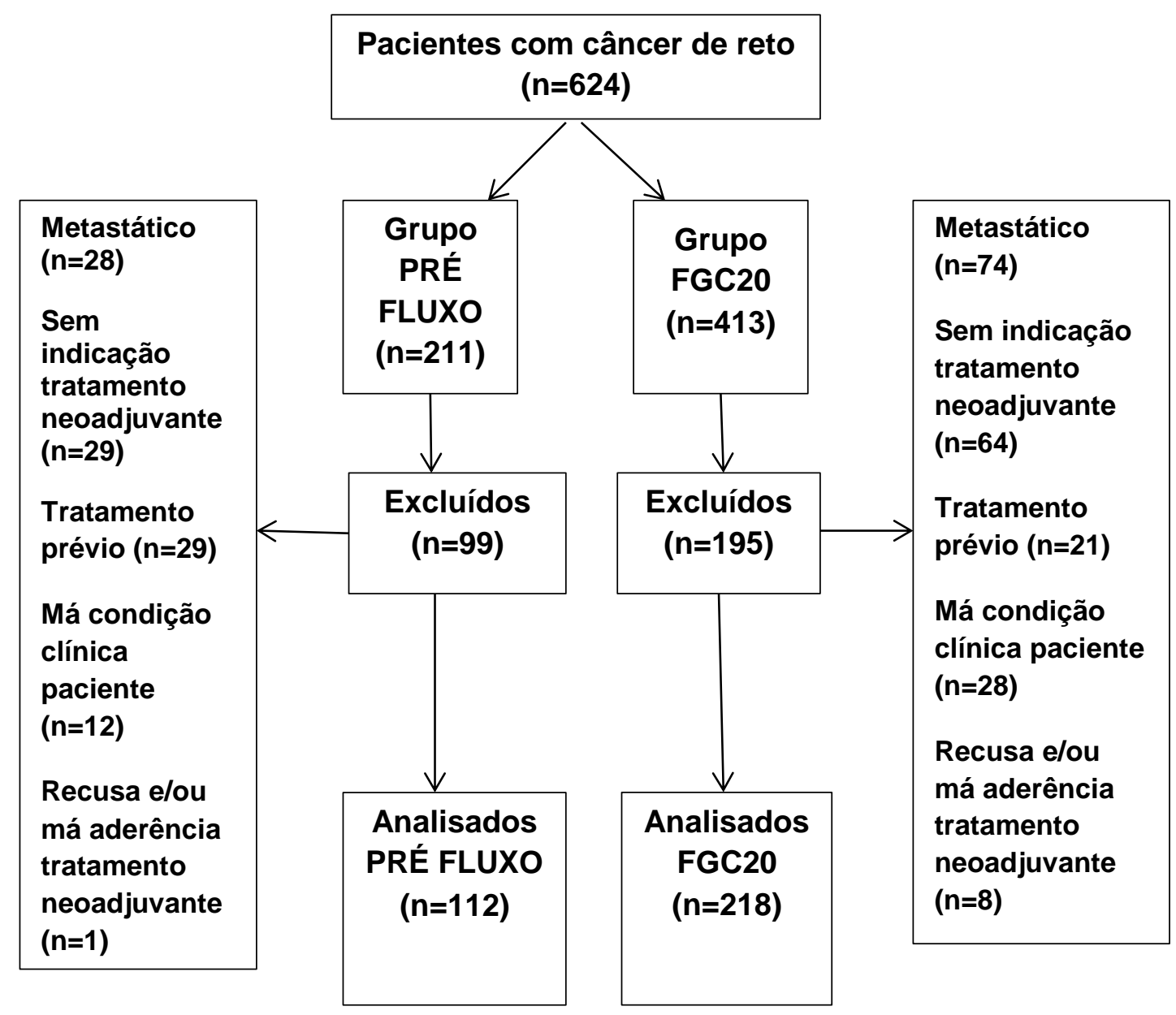

O grupo PRÉ FLUXO correspondeu a 33,9\% do total de pacientes, e o grupo FGC20 representou $66,1 \%$ do total de pacientes. Não houve diferença ente os grupos em relação à distribuição por sexo $(p=0,788)$. A média de idade no grupo FGC20 foi de 62,1 anos e a mediana de 63,2 anos (vmin 30,8 - vmax 85,2), sendo significativamente maior que o grupo PRÉ FLUXO $(p=0,026)$ (tabela 1). 
Os grupos diferiram significativamente $(p<0,001)$ em relação à distribuição dos pacientes segundo o estádio clínico inicial. No grupo PRÉ FLUXO, houve predomínio de pacientes no estádio clínico inicial IIIB e IIA (36,6\% e 33\%, respectivamente). Na coorte FGC20, houve uma maior proporção de pacientes no estádio IIIC (35,8\%), seguido pelo estádio IIIB $(30,7 \%)$ (tabela 1$)$

Não houve diferença estatisticamente significante entre os grupos, em relação aos estádios patológicos $(p=0,632)$ (tabela 1). 
Tabela 1- Distribuição, dados demográficos, estádio clínico inicial, inicial agrupado e patológico de pacientes observados nos grupos PRÉ FLUXO e FGC20, em pacientes com câncer de reto, ICESP, 2008-2013.

\begin{tabular}{|c|c|c|c|c|}
\hline & & $\begin{array}{c}\text { PRÉ FLUXO } \\
\text { N (\%) }\end{array}$ & $\begin{array}{c}\text { FGC20 } \\
\text { N (\%) }\end{array}$ & $p$-valor \\
\hline $\begin{array}{l}\text { Pacientes } \\
(\mathrm{N}=330)\end{array}$ & & $112(33,9)$ & $218(66,1)$ & \\
\hline Sexo & $\begin{array}{l}\text { feminino } \\
\text { masculino }\end{array}$ & $\begin{array}{l}49(43,8) \\
63(56,3)\end{array}$ & $\begin{array}{c}92(42,2) \\
126(57,8)\end{array}$ & $p=0,788$ \\
\hline Idade (anos) & $\begin{array}{c}\text { média } \\
\text { mediana } \\
\text { vmin-vmax }\end{array}$ & $\begin{array}{c}59,0 \\
60,3 \\
23,0-85,4\end{array}$ & $\begin{array}{c}62,1 \\
63,2 \\
30,8-85,2\end{array}$ & $p=0,026$ \\
\hline Estádio* Inicial & $\begin{array}{l}\text { I } \\
\text { IIA } \\
\text { IIB } \\
\text { IIIA } \\
\text { IIIB } \\
\text { IIIC }\end{array}$ & $\begin{array}{c}6(5,4) \\
37(33,0) \\
4(3,6) \\
10(8,9) \\
41(36,6) \\
14(12,5)\end{array}$ & $\begin{array}{c}12(5,5) \\
28(12,8) \\
13(6,0) \\
20(9,2) \\
67(30,7) \\
78(35,8)\end{array}$ & $p<0,001$ \\
\hline $\begin{array}{l}\text { Estádio* Inicial } \\
\text { Agrupado }\end{array}$ & $\begin{array}{l}\text { I } \\
\text { II } \\
\text { III }\end{array}$ & $\begin{array}{c}6(5,4) \\
41(36,6) \\
65(58,0)\end{array}$ & $\begin{array}{c}12(5,5) \\
41(18,8) \\
165(75,7)\end{array}$ & $p=0,002$ \\
\hline $\begin{array}{l}\text { Estádio* } \\
\text { Patológico }\end{array}$ & $\begin{array}{l}0 \\
I \\
\text { IIA } \\
\text { IIB } \\
\text { IIIA } \\
\text { IIIB } \\
\text { IIIC } \\
\text { IV }\end{array}$ & $\begin{array}{c}24(21,4) \\
22(19,6) \\
30(26,8) \\
4(3,6) \\
11(9,8) \\
13(11,6) \\
7(6,3) \\
1(0,9)\end{array}$ & $\begin{array}{c}40(18,3) \\
51(23,4) \\
49(22,5) \\
12(5,5) \\
12(5,5) \\
35(16,1) \\
16(7,3) \\
3(1,4)\end{array}$ & $p=0,632$ \\
\hline
\end{tabular}

Foram selecionados os seguintes indicadores de monitoramento de resultados da implantação do FGC20, baseados em resultados esperados do modelo lógico, destacados em vermelho na figura 2: intervalo de tempo entre a inserção do Flag e a realização da primeira consulta; intervalo de tempo entre o final da nCRT e a realização da cirurgia; e intervalo de tempo entre a primeira consulta e a cirurgia (tabela 2). 
O indicador "intervalo de tempo entre a inserção do Flag e a realização da primeira consulta" tem como meta o prazo máximo de 15 dias, conforme a definição das equipes.

O indicador "intervalo de tempo entre o final da nCRT e a realização da cirurgia" tem como meta o prazo de 14 semanas, considerando uma margem de 2 semanas a mais em relação ao prazo ideal definido pelas equipes médicas.

O indicador "intervalo de tempo entre a primeira consulta e a cirurgia" tem como meta 189 dias ou 27 semanas, considerando o fluxograma descrito e uma margem de duas semanas a mais em relação ao prazo ideal definido pelas equipes médicas.

A tabela 2 apresenta a porcentagem de pacientes do grupo FGC20 que atingiram as metas esperadas. $66,3 \%$ dos pacientes observados no período realizaram a primeira consulta após a inserção do Flag no prazo esperado de 15 dias.

$75,2 \%$ dos pacientes do grupo FGC20 ficaram dentro da meta esperada de 14 semanas para o intervalo entre o final da nCRT e a cirurgia, e $72,7 \%$ dos pacientes completaram todas as etapas do FGC20 no intervalo menor ou igual a 189 dias (tabela 2).

Os intervalos entre as etapas do tratamento foram significativamente diferentes entre os grupos (tabela 2), e todos os intervalos de tempo foram maiores no grupo PRÉ FLUXO, comparados ao Grupo FGC20. 
Tabela 2 - Indicadores de monitoramento do Modelo Lógico do FGC20 e intervalos entre as etapas de primeira consulta médica, tratamento neoadjuvante e cirurgia, em pacientes com câncer de reto, ICESP, 2011-2013.

\begin{tabular}{|c|c|c|c|c|c|c|}
\hline & $\begin{array}{l}\text { Meta do } \\
\text { Indicador }\end{array}$ & $\begin{array}{c}\text { Pac } \\
\text { FGC20 } \\
\leq \text { meta } \\
(\%)\end{array}$ & FGC20 & $\begin{array}{l}\text { PRÉ } \\
\text { FLUXO }\end{array}$ & $p$-valor & $\begin{array}{l}\text { Variação } \\
\text { PRÉ } \\
\text { FLUXO } \\
\text { /FGC20 }\end{array}$ \\
\hline $\begin{array}{l}\text { Intervalo entre } \\
\text { inserção de Flag e } \\
\text { realização da } \\
\text { 1aㅡonsulta (dias) }^{\text {-a }}\end{array}$ & $\leq 15$ dias & 66,3 & 12,7 (média) & NA & NA & NA \\
\hline $\begin{array}{l}\text { Intervalo entre final } \\
\text { da nCRT e cirurgia } \\
\text { (semanas) }\end{array}$ & $\begin{array}{c}\leq 14 \\
\text { semanas }\end{array}$ & 75,2 & $\begin{array}{c}14,8 \text { (média) } \\
13,2 \\
\text { (mediana) }\end{array}$ & $\begin{array}{c}22,2 \\
\text { (média) } \\
20,0 \\
\text { (mediana) }\end{array}$ & $<0,001$ & $-33 \%$ \\
\hline $\begin{array}{l}\text { Intervalo entre } \\
1^{\text {a}} \text { consulta e } \\
\text { cirurgia (dias) }\end{array}$ & $\leq 189$ dias & 72,7 & $\begin{array}{c}191,8 \\
\text { (média) } \\
176,4 \\
\text { (mediana) }\end{array}$ & $\begin{array}{c}278,2 \\
\text { (média) } \\
261,5 \\
\text { (mediana) }\end{array}$ & $<0,001$ & $-31 \%$ \\
\hline $\begin{array}{l}\text { Intervalo entre } \\
\text { 1ª̂a consulta e início } \text { da nCRT (dias) }\end{array}$ & NA & NA & $\begin{array}{c}\text { 48,2 (média) } \\
39,4 \\
\text { (mediana) }\end{array}$ & $\begin{array}{c}79,7 \\
\text { (média) } \\
71,0 \\
\text { (mediana) }\end{array}$ & $<0,001$ & - 39,5\% \\
\hline $\begin{array}{l}\text { Intervalo entre } \\
\text { início e término da } \\
\text { nCRT (dias) }\end{array}$ & NA & NA & $\begin{array}{c}\text { 40,0 (média) } \\
39,0 \\
\text { (mediana) }\end{array}$ & $\begin{array}{c}43,9 \\
\text { (média) } \\
44,0 \\
\text { (mediana) }\end{array}$ & $<0,001$ & - 8,9\% \\
\hline
\end{tabular}




\subsection{AVALIAÇÃO DOS RECURSOS UTILIZADOS E DESCRIÇÃO DE CUSTOS DO TRATAMENTO DO CÂNCER DE RETO}

A Tabela 3 mostra a utilização de recursos de consultas por especialidade, exames e sessões de radioterapia nos dois grupos. No grupo PRÉ FLUXO, houve maior número de consultas com oncologistas clínicos, TC, RM e sessões de radioterapia $(p<0,001)$. No grupo FGC20, houve maior número de consultas com cirurgião do aparelho digestivo $(p=0,006)$, consultas de radioterapia, avaliação de risco, consultas de multiprofissionais, colonoscopias, check films (radioterapia) e coletas ambulatoriais de exames laboratoriais $(p<0,001)$. 
Tabela 3- Recursos utilizados no período entre a primeiro atendimento médico e 30 dias após a cirurgia, dos pacientes com câncer de reto observados nos grupos PRÉ FLUXO e FGC20, ICESP, 2008-2013, e valores unitários de custos por recursos, referência jan-jul 2015.

\begin{tabular}{|c|c|c|c|c|}
\hline Recurso utilizado & $\begin{array}{c}\text { Valor } \\
\text { Unitário } \\
\mathbf{R} \$\end{array}$ & PRÉ FLUXO & FGC20 & $p$-valor \\
\hline \multicolumn{5}{|l|}{ Consulta por especialidade } \\
\hline Oncologista clínico & 443,38 & 8,5 & 6,4 & $<0,001$ \\
\hline Cirurgião aparelho digestivo & 443,38 & 6,1 & 6,9 & 0,006 \\
\hline Avaliação de risco* & 443,38 & 1,0 & 1,5 & $<0,001$ \\
\hline Anestesista & 443,38 & 1,0 & 1,0 & 0,927 \\
\hline Multiprofissionais ${ }^{\star *}$ & 55,34 & 14,5 & 20,1 & $<0,001$ \\
\hline Médicas (outros) ${ }^{\star \star *}$ & 443.38 & 1,3 & 1,2 & 0,788 \\
\hline Radioterapeuta & 443,38 & $3,4^{\Delta}$ & 7,4 & $<0,001$ \\
\hline Tomografias computadorizadas & 129,85 & 5,8 & 3,5 & $<0,001$ \\
\hline Ressonâncias magnéticas & 263,52 & 1,6 & 0,7 & $<0,001$ \\
\hline Colonoscopias/Retoscopias & 898,49 & 0,8 & 1,9 & $<0,001$ \\
\hline Sessões Radioterapia & 194,21 & 28,5 & 28,0 & $<0,001$ \\
\hline Check Films & - & 12,3 & 14,4 & $<0,001$ \\
\hline Coleta de exames laboratoriais & - & 5,0 & 6,4 & $<0,001$ \\
\hline \multicolumn{5}{|c|}{ 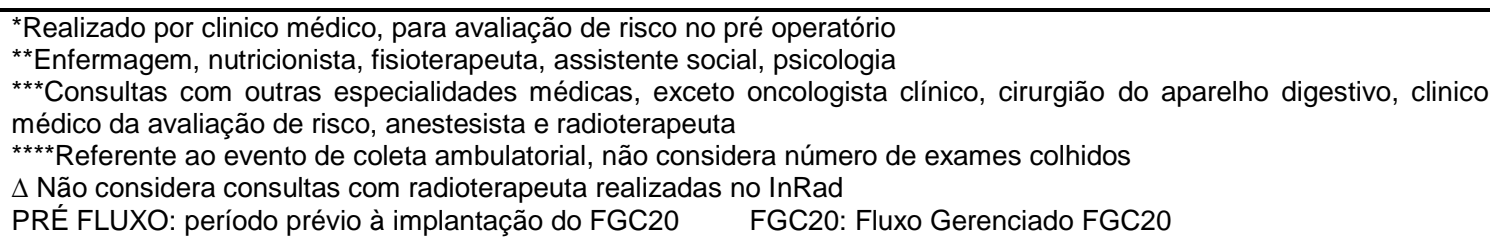 } \\
\hline
\end{tabular}

Os grupos diferiram significativamente quanto a necessidade de atendimento no CAIO e UTI. $62,4 \%$ dos pacientes do grupo FGC20 não registraram atendimentos no CAIO e UTI. $66,1 \%$ e 58,9\% dos pacientes do grupo PRÉ FLUXO tiveram registros de atendimento no CAIO e UTI, respectivamente (tabela 4). No grupo PRÉ FLUXO, houve maior média de 
eventos de atendimentos no CAIO e na UTI, em relação ao grupo FGC20 $(p<0,001)$ (tabela 4).

Tabela 4 - Distribuição de eventos de atendimentos, média de eventos e de dias de internação no CAIO, Unidades de Internação e Unidade de Terapia Intensiva, no período entre a primeiro atendimento médico e 30 dias após a cirurgia, dos pacientes com câncer de reto observados nos grupos PRÉ FLUXO e FGC20, ICESP, 20082013.

\begin{tabular}{lllllc}
\hline \multicolumn{1}{l}{ PRÉ FLUXO } & FGC20 & & p-valor \\
\hline Evento & Sim & Não & Sim & Não & \\
CAIO & $66,1 \%$ & $33,9 \%$ & $37,6 \%$ & $62,4 \%$ & $<0,001$ \\
UI & $100 \%$ & 0 & $100 \%$ & 0 & NA \\
UTI & $58,9 \%$ & $41,1 \%$ & $37,6 \%$ & $62,4 \%$ & $<0,001$ \\
Média de eventos & & & & & \\
Hospital Dia & 0,5 & 0,4 & & 0,272 \\
CAIO* & 1,7 & 0,6 & & $<0,001$ \\
UI & 1,2 & 1,3 & & 0,372 \\
UTI & 0,6 & 0,4 & & $<0,001$ \\
Média de dias de & & & & \\
internação & 10,4 & 10,5 & & 0,398 \\
UI & 1,4 & 1,5 & & 0,006 \\
UTI & & & &
\end{tabular}

NA: não se aplica $\quad$ PRÉ FLUXO: período prévio à implantação do FGC20 $\quad$ FGC20: Fluxo Gerenciado FGC20 *Eventos de atendimento no CAIO, com duração <24 h. CAIO:Centro de Atendimento às Intercorrências Oncológicas UI: Unidade de Internação UTI: Unidade de Terapia Intensiva 
A tabela 6 apresenta a utilização do recurso de quimioterapia. 26,8\% dos pacientes do grupo PRÉ FLUXO realizaram quimioterapia de indução, comparados a $0,5 \%$ dos pacientes do grupo FGC20 ( $p<0,001)$. Neste grupo, o protocolo FULV foi utilizado na totalidade dos pacientes.

Tabela 6 - Utilização de quimioterapia no período entre a primeiro atendimento médico e 30 dias após a cirurgia, pelos pacientes com câncer de reto, observados nos grupos PRÉ FLUXO e FGC20, ICESP, 2008-2013.

\begin{tabular}{|c|c|c|c|c|}
\hline & PRÉ FLUXO (\%) & FGC20 (\%) & $p$-valo & \\
\hline \multicolumn{5}{|l|}{ QT Indução } \\
\hline Sim & $30(26,8)$ & $1(0,5)$ & \multirow{2}{*}{\multicolumn{2}{|c|}{$<0,001$}} \\
\hline Não & $82(73,2)$ & $217(99,5)$ & & \\
\hline \multicolumn{5}{|c|}{ Protocolo QT Indução } \\
\hline mFlox & $29(25,9)$ & $1(0,5)$ & \multirow{2}{*}{\multicolumn{2}{|c|}{ NA }} \\
\hline QUASAR & $1(0,9)$ & 0 & & \\
\hline \multicolumn{5}{|c|}{ Protocolo QT neoadjuvante } \\
\hline \multirow[t]{2}{*}{ FULV } & $92(82,1)$ & $218(100)$ & \multirow[t]{3}{*}{ NA } & \multirow[t]{2}{*}{ mFlox } \\
\hline & $8(7,1)$ & 0 & & \\
\hline outros & $12(10,7)$ & 0 & & \\
\hline
\end{tabular}

NA: não se aplica QT: quimioterapia

FULV: ácido folínico (20 mg/m², IV, bolus D1a D5) e 5-fluorouracil ( $350 \mathrm{mg} / \mathrm{m}^{2}$, IV, bolus D1 a D5) nas semanas 1 e 5 da radioterapia

mFlox: oxaliplatina (85 mg/ $\mathrm{m}^{2}$ IV 2 horas, semanas 1,3,5), ácido folínico (20 mg/ m² IV bolus, semanas 1,2,3,4,5,6) e 5fluorouracil $\left(500 \mathrm{mg} / \mathrm{m}^{2}\right.$ IV bolus, semanas $\left.1,2,3,4,5,6\right)$

QUASAR: ácido folínico (50 mg/m² IV, semanal) + 5-fluorouracil ( $370 \mathrm{mg} / \mathrm{m}^{2} \mathrm{IV}$, semanal)

PRÉ FLUXO: período prévio à implantação do FGC20 FGC20: Fluxo Gerenciado FGC20 
Para o cálculo de custo da quimioterapia (tabela 7) dos protocolos mFLOX e FULV foram utilizados valores de junho de 2015 de materiais, medicamentos, recursos humanos e infraestrutura. As doses de medicamentos foram as preconizadas no Manual de Condutas em Oncologia ${ }^{35}$, utilizando o valor médio de superfície corpórea de $1,8 \mathrm{~m}^{2}$, para cálculo das doses de medicamentos.

Tabela 7 - Custo em Reais de junho 2015, quimioterapia protocolo mFLOX e protocolo FULV, ICESP.

\begin{tabular}{|c|c|c|c|c|c|c|c|}
\hline $\mathrm{mFLOX}^{\star \star}$ & $D^{*} 1$ & $D^{*} 8$ & $D^{*} 15$ & $D^{\star} 22$ & $D^{*} 29$ & $D^{*} 36$ & Total \\
\hline Custo & 167,18 & 167,51 & 167,18 & 167,51 & 167,18 & 107,44 & 944,00 \\
\hline 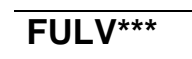 & $D^{*} 1$ & $D^{*} 2$ & $D^{*} 3$ & $D^{*} 4$ & $\mathrm{D} * 5$ & & Total \\
\hline $1^{\circ}$ ciclo & 166,52 & 166,52 & 166,52 & 166,52 & 166,52 & & 832,60 \\
\hline $2^{\circ}$ ciclo & 166,52 & 166,52 & 166,52 & 166,52 & 166,52 & & 832,60 \\
\hline Total & 333,04 & 333,04 & 333,04 & 333,04 & 333,04 & & 1665,20 \\
\hline
\end{tabular}

A Tabela 8 demonstra o cálculo do custo do procedimento cirúrgico. 0 valor de referência do valor do minuto cirúrgico foi obtido pela média de janeiro a julho de 2015, e considera o valor do centro cirúrgico, de custos fixos, variáveis e rateios em recursos humanos, materiais, medicamentos, infraestrutura e exames realizados. Para o custo dos procedimentos, utilizou-se a mediana de tempo de cirurgias disponível em banco de dados do setor de custos: no período de janeiro a julho de 2014, a mediana de tempo de 47 
retossigmoidectomias abertas foi de 385 minutos, e a mediana de tempo de 30 cirurgias de retossigmoidectomias por videolaparoscopia foi de 459 minutos. No período de janeiro a dezembro de 2013 foram analisadas 40 cirurgias de amputação de reto, com mediana de tempo de 460 minutos.

$\mathrm{Na}$ coleta de dados do presente estudo, foram encontradas outras nomenclaturas de cirurgias realizadas, tais como exenteração pélvica e laparotomia exploradora. Nestes casos, foram adotados os mesmos parâmetros da cirurgia de amputação de reto, para cálculo do custo do procedimento.

Tabela 8 - Custo do procedimento cirúrgico, ICESP, referência minuto cirúrgico jan-jul 2015, ICESP.

\begin{tabular}{lccc}
\hline & $\begin{array}{c}\text { Retossigmoidectomia } \\
\text { Aberta }^{1}\end{array}$ & $\begin{array}{c}\text { Retossigmoidectomia } \\
\text { Video }^{2}\end{array}$ & Amputação de reto \\
\hline tempo de cirurgia & $385^{\star}$ & $459^{* *}$ & $460^{* \star *}$ \\
(mediana em min) & 16,90 & 16,90 & 16,90 \\
Valor minuto cirúrgico $(\mathrm{R} \$)$ & $6.506,50$ & $7.757,10$ & $7.774,00$ \\
\hline Custo do procedimento(R\$) &
\end{tabular}

${ }^{*}$ mediana de tempo de 47 cirurgias, jan-jul 2014

**mediana de tempo de 30 cirurgias, jan-jul 2014

***mediana de tempo de 40 cirurgias, jan-dez 2013

${ }^{1}$ Retossigmoidectomia aberta

${ }^{2}$ Retossigmoidectomia por videolaparoscopia

min: minutos

O custo do tratamento foi calculado para cada paciente considerando: número de consultas médicas (oncologista clínico, cirurgião do aparelho digestivo, clínico geral, anestesistas e outras especialidades médicas), consultas de odontólogos, consultas multiprofissionais (enfermeiros, nutricionistas, fisioterapeutas, psicólogos, assistentes sociais), TC, RM, colonoscopias e/ou retoscopias, sessões de radioterapia, número de eventos e 
diárias de internação no CAIO, diárias em hospital dia, diárias em UI, diárias em UTI, quimioterapia de indução, quimioterapia neoadjuvante e cirurgia (retossigmoidectomia aberta, retossigmoidectomia por videolaparoscopia, amputação de reto, exenteração pélvica e laparotomia exploradora).

Não foi possível utilizar o número de consultas de radioterapia, por impossibilidade de coleta da informação de consultas de radioterapia realizadas em outro instituto, ocorridos no grupo PRÉ FLUXO. Também não se utilizou o número de coletas ambulatoriais, pois identificou-se que parte dos pacientes do PRÉ FLUXO realizaram coletas de exames laboratoriais em esquema de internação (no pré operatório da cirurgia), e não ambulatorialmente.

Do total de 112 pacientes do grupo PRÉ FLUXO, 16 pacientes foram excluídos do cálculo, por terem realizado radioterapia em outro serviço, não tendo sido possível obter a informação de número de sessões, restando um total de 96 pacientes. Para o grupo FGC20, os dados de recursos utilizados estavam completos para os 218 pacientes observados.

No grupo PRÉ FLUXO, o menor valor de custo por paciente tratado foi de $R \$ 27.505,80$ e o maior valor foi de $R \$ 106.892,93$. Para este grupo, a média de custo por paciente tratado foi de $R \$ 40.935,68$ e mediana foi de $R \$$ 37.948,05 (tabela 9, figura 4).

No grupo FGC20, encontrou-se o menor valor de custo por paciente tratado de $R \$ 26.081,95$ e o maior valor de $R \$ 140.820,25$. No FGC20, a média 
de custo por paciente tratado foi de $R \$ 40.368,18$ e a mediana foi de $R \$$ 35.341,32 (tabela 9, figura 4).

Não houve diferenças estatisticamente significantes entre os grupos, de valores de custo por paciente tratado $(p=0,125)$ (tabela 9).

Tabela 9 - Custo por paciente tratado, segundo Grupo PRÉ FLUXO e FGC20, ICESP, 2008-2013.

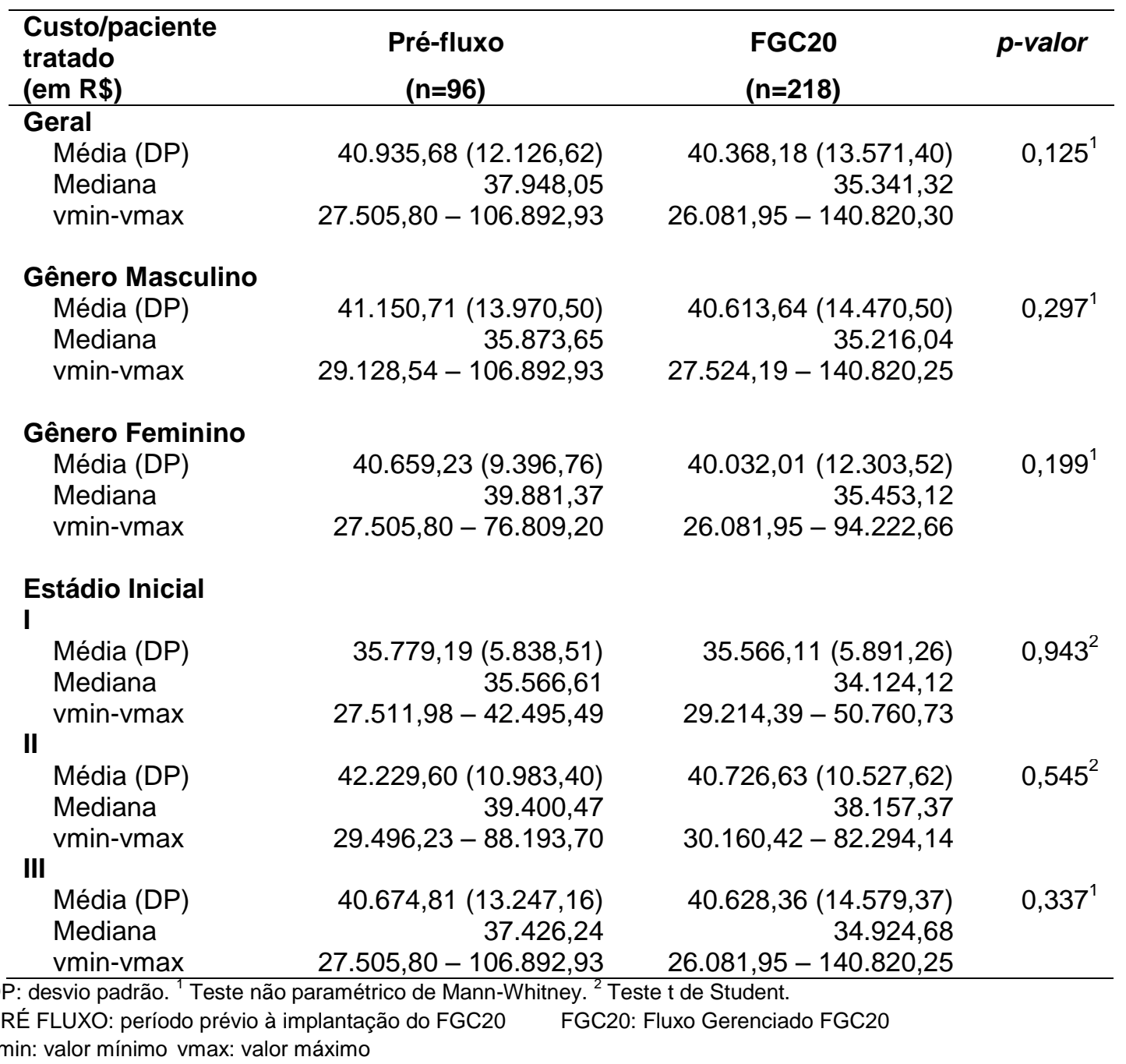


Figura 4 - Gráfico de boxplot dos custos segundo Pré-fluxo e FGC20, ICESP 20082013.

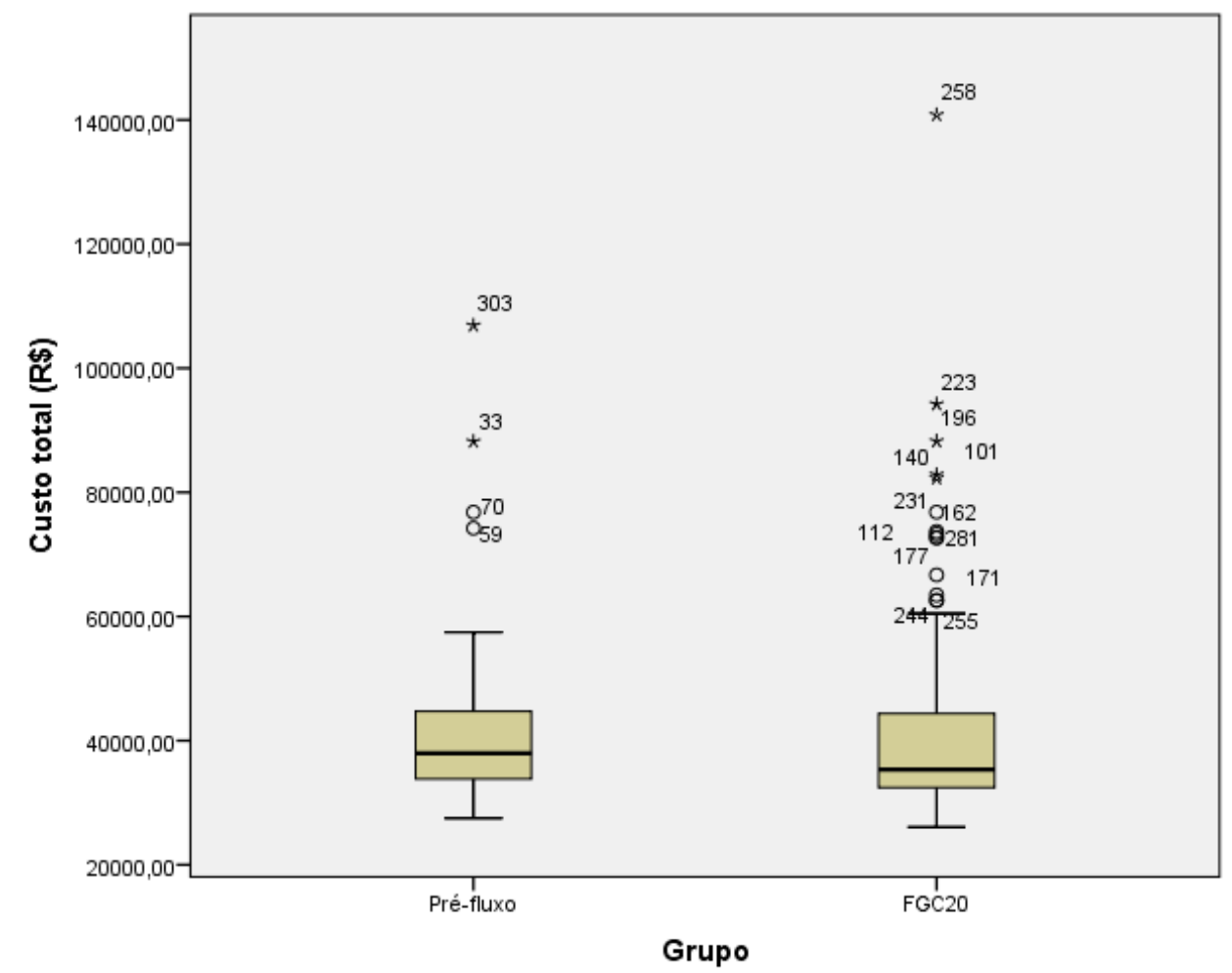

PRÉ FLUXO: período prévio à implantação do FGC20 FGC20: Fluxo Gerenciado FGC20

A tabela 10 mostra os recursos utilizados nos grupos PRÉ FLUXO e FGC20, bem como o valor unitário de custo por recurso, com valor de referência de janeiro a julho de 2015. Apresenta o cálculo do custo total por recurso utilizado e o custo total dos grupos. O custo total dos pacientes do PRÉ FLUXO foi de $R \$ 3.929 .825,75$ e do FGC20 $R \$$ 8.800.264,19. Em negrito, a tabela 10 destaca o valor dos custos segundo os principais agrupamentos de recursos utilizados no tratamento dos pacientes. O agrupamento de recursos que teve o custo mais elevado em ambos os grupos foi o de diárias, incluindo diárias em UI, UTI, hospital dia e diárias e eventos no Centro de Atendimento 
às Intercorrências Oncológicas. Totalizou R\$1.465.595,00 no PRÉ FLUXO e $\mathrm{R} \$ 3.259 .609,36$ no FGC20, representando $37 \%$ do total de custos em ambos os grupos (figura 5).

O segundo agrupamento mais representativo em relação aos recursos utilizados foi o de consultas médicas e multiprofissionais. Estão incluídas todas as consultas médicas com oncologistas, cirurgiões, clínicos, anestesiologistas e outras especialidades médicas (exceto radioterapia, onde não foi possível o levantamento de consultas de radioterapia realizadas no grupo PRÉ FLUXO, por isto excluído da análise) e consulta de odontologista, bem como as consultas multiprofissionais de enfermeiros, nutricionistas, fisioterapeutas, assistentes sociais e psicólogos. O custo no PRÉ FLUXO foi de $\mathrm{R} \$ 843.790,92$, e no FGC20 foi de $R \$ 1.884 .421,30$ (tabela 10). A representatividade em ambas as coortes foi de $21 \%$ do custo total (figura 5).

O agrupamento cirurgias englobou todos os tipos de cirurgias: retossigmoidectomias abertas, por vídeolaparoscopia, amputações de reto, exenterações e laparotomias exploradoras utilizadas para a realização da cirurgia principal. O custo no PRÉ FLUXO foi de R\$703.834,30, e no FGC20, de $R \$ 1.590 .644,90$ (tabela 10). Em ambos, este agrupamento representou $18 \%$ do valor total do custo (figura 5 ).

A realização de sessões de radioterapia representou 14\% (figura 5) do total de custos de ambos os grupos, com o valor de $\mathrm{R} \$ 538.738,54$ para o PRÉ FLUXO e de R\$1.184.681,00 para o FGC20 (tabela 10). 
Os exames de apoio diagnóstico de TC, RM e colonoscopias/retoscopias totalizaram $\mathrm{R} \$ 192.519,79$ de custo no PRÉ FLUXO e $\mathrm{R} \$ 516.950,03$ de custo para os pacientes do FGC20 (tabela 10). Representaram 5\% do total de custos do grupo PRÉ FLUXO e 6\% do grupo FGC20 (figura 5).

As sessões de quimioterapia totalizaram $\mathrm{R} \$ 185.347,20$ no PRÉ FLUXO e $R \$ 363.957,60$ no FGC20 (tabela 10). Do total de custos estes valores representaram 5\% e 4\% do total de custos dos grupos PRÉ FLUXO e FGC20, respectivamente (figura 5). 
Tabela 10 - Recursos utilizados e custos do tratamento dos pacientes com câncer de reto, em Reais de jan-jul 2015, nos grupos PRÉ FLUXO e FGC20, ICESP, 2008-2013.

\begin{tabular}{|c|c|c|c|c|c|}
\hline & $\begin{array}{r}\text { Valor } \\
\text { unitário }(\mathbf{R} \$)\end{array}$ & $\begin{array}{r}\text { Total } \\
\text { PréFluxo } \\
(n=96)\end{array}$ & $\begin{array}{r}\text { Total } \\
\text { FGC20 } \\
(n=218)\end{array}$ & $\begin{array}{l}\text { Custo PRÉ } \\
\text { FLUXO (R\$) }\end{array}$ & $\begin{array}{r}\text { Custo FGC20 } \\
(\mathrm{R} \$)\end{array}$ \\
\hline C. Médica* & 443,38 & 1.720 & 3.696 & $762.613,60$ & $1.638 .732,48$ \\
\hline C. Multiprof. ${ }^{* *}$ & 55,34 & 1.460 & 4.388 & $80.796,40$ & $242.831,92$ \\
\hline C.odonto. & 190,46 & 2 & 15 & 380,92 & $2.856,90$ \\
\hline Total Consultas & - & - & - & $843.790,92$ & $1.884 .421,30$ \\
\hline $\mathrm{TC}$ & 129,85 & 573 & 764 & $74.404,05$ & $99.205,40$ \\
\hline $\mathrm{RM}$ & 263,52 & 155 & 143 & $40.845,60$ & $37.683,36$ \\
\hline Colonoscopias $\Delta$ & 898,49 & 86 & 423 & $77.270,14$ & $380.061,27$ \\
\hline Total exames & - & - & - & $192.519,79$ & $516.950,03$ \\
\hline Sessões RT & 194,21 & 2.774 & 6.100 & $538.738,54$ & $1.184 .681,00$ \\
\hline Ev. CAIO ${ }^{* * *}$ & $\begin{array}{r}546,85 / \\
497,13\end{array}$ & 158 & 141 & $86.402,30$ & $70.095,33$ \\
\hline Di. CAIO & $2.386,25$ & 59 & 106 & $140.788,75$ & $252.942,50$ \\
\hline Di. UI & 941,39 & 936 & 2.179 & $881.141,04$ & $2.051 .288,81$ \\
\hline Di.UTI & $2.518,57$ & 131 & 336 & $329.932,67$ & $846.239,52$ \\
\hline Di.Hospital Dia & 488,04 & 56 & 80 & $27.330,24$ & $39.043,20$ \\
\hline Total Diárias & - & - & - & $1.465 .595,00$ & $3.259 .609,36$ \\
\hline QT indução & 944,00 & 27 & 1 & $25.488,00$ & 944,00 \\
\hline QT neoadj. & $1.665,20$ & 96 & 218 & $159.859,20$ & $363.013,60$ \\
\hline Total QT & - & - & - & $185.347,20$ & $363.957,60$ \\
\hline Cg Reto. Aberta & $6.506,50$ & 33 & 81 & $214.714,50$ & $527.026,50$ \\
\hline Cg Reto. Video & $7.757,10$ & 38 & 84 & $294.769,80$ & $651.596,40$ \\
\hline Cg outras ${ }^{* * * *}$ & $7.774,00$ & 25 & 53 & $194.350,00$ & $412.022,00$ \\
\hline Total Cirurgia & - & - & - & $703.834,30$ & $1.590 .644,90$ \\
\hline Custo Total & - & - & - & $3.929 .825,75$ & $8.800 .264,19$ \\
\hline $\begin{array}{l}\text { Média custo/ } \\
\text { pac. tratado }\end{array}$ & - & - & - & $40.935,68$ & $40.368,18$ \\
\hline $\begin{array}{l}\text { Mediana custo/ } \\
\text { pac. tratado }\end{array}$ & - & - & - & $37.948,05$ & $35.341,32$ \\
\hline
\end{tabular}


CAIO:Centro de Atendimento às Intercorrências Oncológicas

Di.:Diárias UI: Unidade de Internação UTI: Unidade de Terapia Intensiva

TC:tomografia computadorizada RM:ressonância magnética QT:quimioterapia RT:radioterapia Pac:paciente $\mathrm{Cg}$ :cirurgia Reto:retossigmoidectomia

PRÉ FLUXO: período prévio à implantação do FGC20 FGC20: Fluxo Gerenciado FGC20

Figura 5 - Distribuição dos agrupamentos de custos, grupos PRÉ FLUXO e FGC20, ICESP 2008-2013.

\section{Distribuição de Custos Pré Fluxo \\ Distribuição de Custos FGC20}

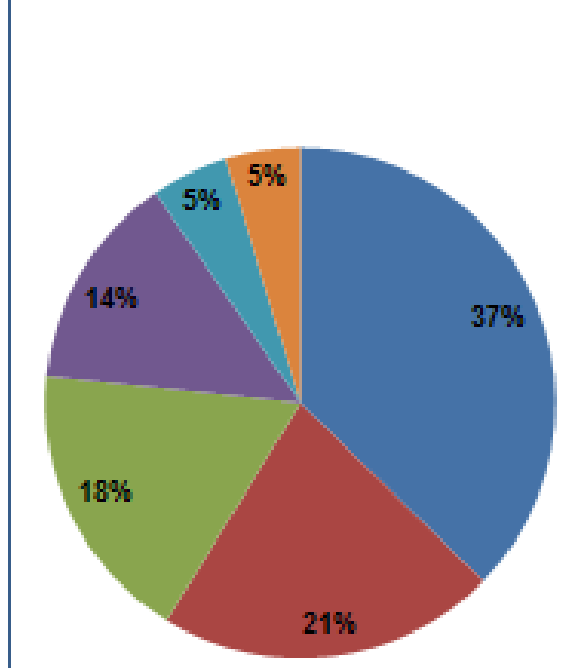

- Diá rias

- Consultas

m Cirurgias

- RT

Ex Imagem e

Scopias

$=\mathrm{QT}$

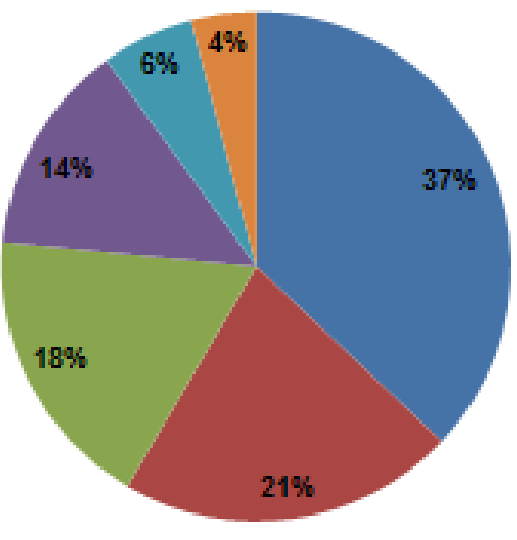

PRÉ FLUXO: período prévio à implantação do FGC20

FGC20: Fluxo Gerenciado FGC20

RT - radioterapia

QT - quimioterapia

Ex Imagem: exames de imagem 


\subsection{SOBREVIDA GLOBAL}

As informações do status vital dos pacientes, se vivos ou falecidos, e as datas dos últimos registros de atendimento foram obtidas em $100 \%$ dos pacientes dos grupos PRÉ FLUXO e FGC20. A sobrevida global foi considerada desde a data do diagnóstico inicial do tumor até o óbito (por qualquer causa) ou última informação.

O tempo médio de sobrevida global foi de 5,99 (IC95\% 5,59-6,40) e 7,01 (IC95\% 6,47 - 7,54) anos para os grupos PRÉ FLUXO e FGC20, respectivamente (tabela 11). Não houve diferença estatisticamente significante entre as curvas de sobrevida global dos grupos $(p=0,83)$ (figura 6).

Tabela 11 - Tempo médio de sobrevida global, em anos, nos grupos PRÉ FLUXO e FGC20, ICESP.

\begin{tabular}{|c|c|c|c|c|c|c|}
\hline \multirow{2}{*}{ Grupo } & \multirow{2}{*}{$\begin{array}{c}\text { Média } \\
\text { Anos (EP) }\end{array}$} & \multirow{2}{*}{ IC95\% } & \multicolumn{4}{|c|}{ Probabilidade de sobrevida } \\
\hline & & & 1-ano & 2-anos & 3-anos & 5-anos \\
\hline PRÉ FLUXO & $5,99(0,21)$ & $5,59-6,40$ & $99,1 \%$ & $93,8 \%$ & $87,5 \%$ & $67,2 \%$ \\
\hline FGC20 & $7,01(0,27)$ & $6,47-7,54$ & $94,5 \%$ & $86,6 \%$ & $80,5 \%$ & $68,9 \%$ \\
\hline TOTAL & $6,77(0,21)$ & $6,37-7,17$ & & & & \\
\hline
\end{tabular}

PRÉ FLUXO: período prévio à implantação do FGC20 FGC20: Fluxo Gerenciado FGC20

EP: Erro padrão IC95\%: 95\% intervalo de confiança de 95\% para o tempo médio de sobrevida 
Figura 6. Curva de sobrevida global nos grupos PRÉ FLUXO e FGC20, ICESP

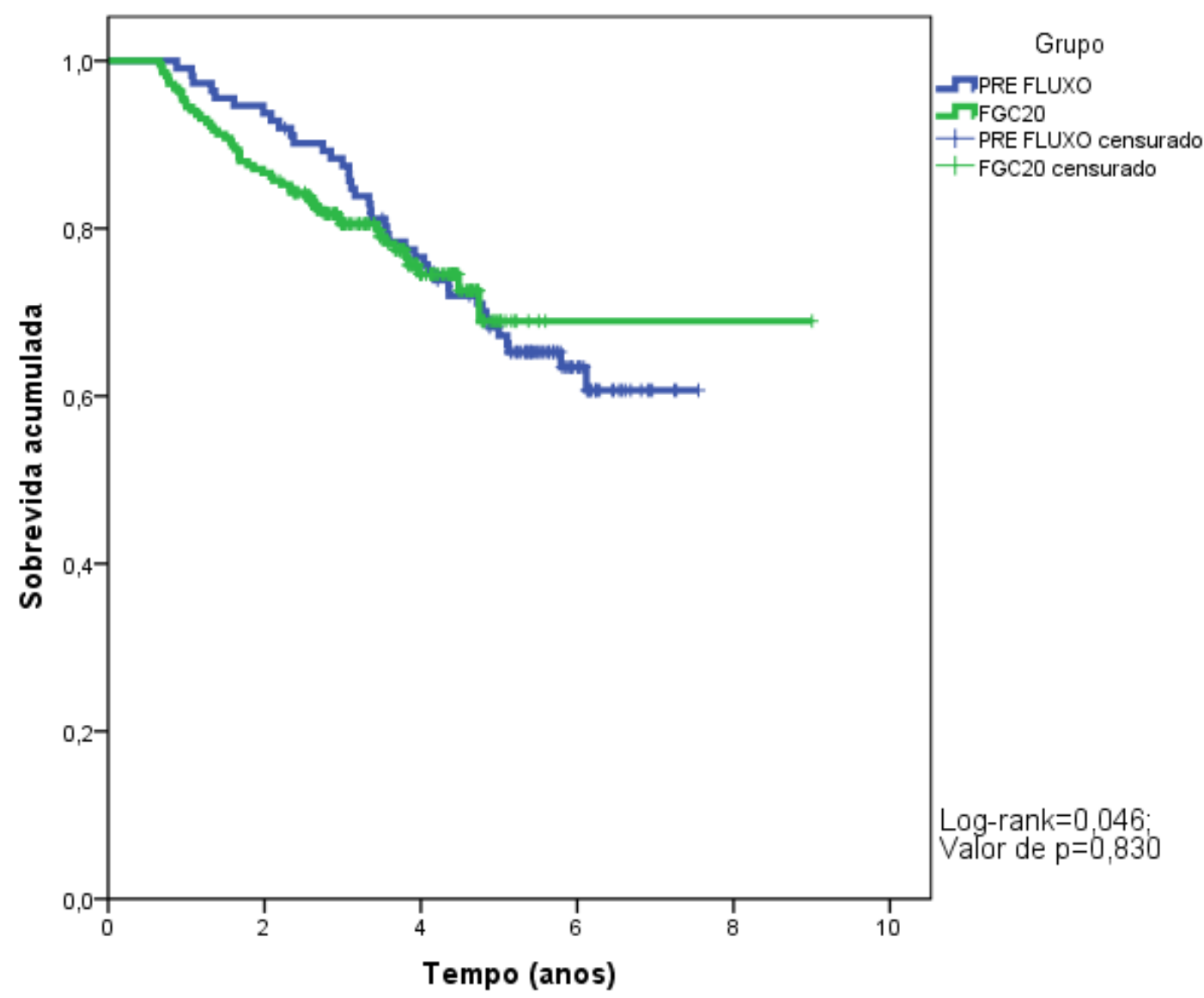


DISCUSSÃO 


\section{DISCUSSÃO}

O FGC20 é um marco assistencial-administrativo no ICESP, por associar, de forma sistemática, o apoio administrativo às necessidades assistenciais do cuidado multidisciplinar ao paciente. Relatar a abordagem multidisciplinar, as soluções desenvolvidas, os pontos críticos, as melhorias e mensurar os impactos assistenciais decorrentes da sua implantação foram a motivação para o desenvolvimento do presente estudo. A implantação do FGC20 trouxe redução de todos os intervalos de tempo entre as etapas do tratamento, além de racionalização no número de consultas de oncologistas, exames de TC e RM, durante o período de tratamento do paciente até a realização da cirurgia. Apesar dessas melhorias no processo terapêutico, diferenças estatisticamente significantes não foram encontradas no custo por paciente tratado e na sobrevida global comparando-se os grupos PRÉ FLUXO e FGC20.

A oncologia é uma especialidade médica que se norteia por fundamentos, protocolos e diretrizes, e tem como premissa a abordagem multidisciplinar. A inter-relação entre as diversas especialidades e equipe multiprofissional é fundamental para o cuidado ao paciente.

O conceito de multidisciplinaridade é recomendado pelo National Comprehensive Cancer Network, através do Clinical Practice Guidelines in Oncology, que preconiza a abordagem multidisciplinar com oncologistas, gastroenterologistas, cirurgiões oncológicos, radioterapeutas e radiologistas ${ }^{38}$. Prática de algumas instituições é a estruturação do time multidisciplinar em 
reuniões sistemáticas, constituindo "Tumor boards"39". Porém, há escassez de pesquisas que demonstrem a efetividade da equipe multisdisciplinar ${ }^{40}$, e há autores que levantam a necessidade de se avaliar o custo efetividade da prática multidisciplinar baseada no contexto local ${ }^{41,42,43}$.

A execução de um protocolo clínico na prática diária é um desafio: depende de esforços individuais no sentido de adequar os recursos às diretrizes. Especialmente em hospitais de alta demanda e recursos limitados, como hospitais públicos, os profissionais estabelecem acordos e alteram agendas, segundo julgamento próprio em relação às prioridades. Um fator agravante é o distanciamento entre os setores assistencial e administrativo: por um lado, a equipe assistencial percebe a administração como setor de controle burocrático com foco em aumento de produtividade; por outro lado, o setor administrativo percebe os profissionais assistenciais como conhecedores técnicos sem experiência em gestão e responsáveis por número excessivo de solicitações de exames subsidiários e utilização de insumos.

Dados de literatura ${ }^{7}$ demonstram a necessidade de estudos de avaliação de protocolos clínicos, que verifiquem as propostas das intervenções, as mudanças de comportamento, o contexto, e que identifiquem os fatores críticos de sucesso.

A modelização foi a estratégia utilizada no presente estudo, para documentar o histórico da implantação. Há autores ${ }^{44}$ que distinguem a terminologia da modelização em teoria de programa e teoria de processo, outros diferenciam a teoria de programa e modelo lógico, e muitos utilizam indiferentemente as duas expressões. Há autores ${ }^{45}$ que, de outra forma, 
interpretam a modelização em teoria da implantação e teoria do programa. Considerando, de modo geral, a existência de três modelos principais (causal, teórico e lógico operacional) ${ }^{13}$, o presente estudo utilizou a construção do modelo lógico operacional para explicitar os vínculos entre as estruturas, os processos e os resultados do FGC20, descrevendo o funcionamento real da intervenção implantada a partir da experiência e intuição dos participantes, e não a partir de um modelo formal existente.

Na modelização, as atividades e objetivos elencados mostram, de forma não explícita, as dificuldades existentes na época da implantação.

O primeiro objetivo, de envolver o corpo clínico, foi decorrente da necessidade de disseminar e uniformizar as condutas entre as diversas especialidades médicas e encontrar soluções para assegurar a sequência do tratamento definido. A indisponibilidade do recurso no prazo necessário gerava adaptações: como exemplo, por dificuldades no agendamento de radioterapia, havia utilização de quimioterapia de indução até a efetivação do agendamento de quimioterapia e radioterapia concomitantes. Outra dificuldade apontada por todas as equipes era a dificuldade no agendamento da cirurgia após o tratamento neoadjuvante. No contexto do período, a sequência compartimentada de atendimento do paciente com câncer de reto prejudicava a fluidez do tratamento, pois o encaminhamento a outra equipe ou a nova etapa era feito apenas após a finalização da anterior.

O segundo objetivo, de envolver a equipe de apoio administrativo, foi necessário para viabilizar a execução do fluxograma na prática diária, de forma 
institucional, com a participação de todas as equipes, assistencial e administrativa.

O terceiro objetivo, de desenvolver soluções para operacionalizar o FGC20 e o quarto objetivo, de desenvolver soluções em sistema informatizado Tasy® estão relacionados às necessidades de comunicação entre as equipes e de racionalização de recursos e processos. Em relação à comunicação, o desenvolvimento do Flag foi necessário para que os envolvidos, tanto administrativos quanto assistenciais, conseguissem identificar o paciente pertencente ao FGC20. Outras soluções associaram benefícios em comunicação, recursos e processos: o carimbo na ficha de regulação, a identificação de vagas de primeira consulta reservadas para o FGC20, a planilha compartilhada para agendamento de sessões de quimioterapia e radioterapia, a planilha de monitoramento ativo "Pacientes ativos; completarealizada-óbito", a definição dos exames de estadiamento e prazos de laudos, e os relatórios CATE permitiram que as diversas equipes pudessem identificar e utilizar racionalmente os recursos do FGC20, de forma simultânea e coordenada.

O objetivo 5 , de treinamento aos colaboradores, foi necessário pela rotatividade de profissionais do setor recepção.

No período da implantação, houve a necessidade de reuniões entre as equipes médicas; entre equipes médicas e multiprofissionais; entre equipes assistenciais e administrativas. Estas interações aproximaram os profissionais e facilitaram o entendimento das respectivas atribuições, valorizando a importância de cada profissional no encadeamento do fluxo. Estas melhorias, 
não mensuráveis, fortaleceram o conceito de integração e provavelmente contribuíram para a criação de ambiente propício a outras inovações no ICESP, como o conceito de clínicas integradas, posteriormente adotado em julho de 2013.

A coleta de informações do período prévio à implantação permitiu a comparação de dois grupos, PRÉ FLUXO e FGC20, quanto aos intervalos de tempo entre etapas, recursos utilizados e descrição de custos do tratamento.

Para a coleta de dados e construção de banco de dados unificado, foi necessário obter relatórios, desenvolver planilhas, realizar dupla checagem de informações e conferir manualmente registros no prontuário eletrônico do paciente. Do universo de 624 pacientes com câncer de reto, 211 foram identificados como PRÉ FLUXO, e 413 como FGC20. Do grupo FGC20 foi necessário verificar registros no prontuário para categorizar o motivo de exclusão do FGC20. 37,9\% dos excluídos do FGC20 foram definidos como metastáticos $(n=74)$ na primeira consulta ou na fase de estadiamento, mostrando a dificuldade de se identificar o paciente como metastático somente através da triagem documental.

Para o grupo PRÉ FLUXO foi necessário identificar ou confirmar as etapas de quimioterapia e radioterapia concomitantes e posterior cirurgia nos registros de prontuário eletrônico para incluir o paciente na análise $(n=112)$. Posteriormente, os motivos para categorizar a exclusão foram identificados nos pacientes em que não se constatou a sequência de tratamento descrita. 
A população analisada diferiu em relação ao estádio clínico inicial do paciente: o grupo FGC20 apresentou maior proporção de pacientes em estádios mais avançados: estádio clínico inicial III para FGC20 (75,5\% dos pacientes), comparado ao grupo PRÉ FLUXO (58\% dos pacientes). Esta diferença pode estar relacionada ao acesso dos pacientes aos serviços da rede básica de saúde e possível prolongamento no tempo dispendido nas estruturas primárias e secundárias para realizar o diagnóstico, até o encaminhamento ao ICESP.

Apesar da diferença no estádio inicial em ambos os grupos, as distribuições de estádios patológicos (obtidos a partir do anátomo-patológico da peça cirúrgica, após o tratamento neoadjuvante com quimioterapia e radioterapia concomitantes) foram semelhantes no PRÉ FLUXO e no FGC20. São necessários estudos específicos para avaliar o grau de resposta ao tratamento neoadjuvante.

O modelo lógico permitiu a identificação de indicadores de monitoramento dos resultados da implantação. A literatura aponta a deficiência de descrições de indicadores de protocolos assistenciais para o câncer colorretal. Ludt et a ${ }^{46}$, em 2013, desenvolveram, a partir de dados da literatura e de consulta a especialistas, uma lista de 52 indicadores de qualidade para cobrir aspectos relevantes no tratamento do câncer colorretal, sendo 11 de procedimentos diagnósticos, 28 de manejo terapêutico, 6 de seguimento e 7 da perspectiva do paciente. Os autores ressaltaram a dificuldade de operacionalização dos indicadores pela falta de especificação das fontes de dados e dos métodos de coleta, e apontaram um predomínio de indicadores 
com foco no tratamento cirúrgico, havendo a necessidade de mensurar qualidade do cuidado durante todo o tratamento.

No presente estudo, os indicadores de intervalos foram selecionados por possibilitarem parâmetros objetivos de mensuração. Durante a implantação, foram discutidos os ideais de prazos entre as etapas de realização da primeira consulta, final da nCRT e cirurgia. Para o estabelecimento da meta, considerou-se uma tolerância de 15 dias a partir do intervalo idealizado. Os resultados demonstraram médias e medianas de intervalos de tempo dentro dos prazos estabelecidos, porém, observou-se uma porcentagem de pacientes "dentro da meta" de $66,3 \%$ para o intervalo de tempo entre a inserção do Flag e a realização da primeira consulta; $75,2 \%$ para o intervalo entre o final da neoadjuvância e a cirurgia e $72,7 \%$ entre a primeira consulta e a cirurgia. Os indicadores evidenciaram oportunidade de melhoria, sendo necessários estudos específicos e ações visando aumentar a porcentagem de pacientes com intervalos dentro dos prazos estabelecidos.

A comparação de intervalos dos grupos PRÉ FLUXO e FGC20 evidenciou melhoria com a implantação do FGC20. Houve uma redução de $39,5 \%$ na média de dias de intervalo entre a primeira consulta médica e o início da nCRT (79,7 média de dias para o PRÉ FLUXO e 48,2 média de dias do FGC20); redução de $33 \%$ na média de semanas de intervalo entre o final da nCRT e a cirurgia (22,2 média de semanas do PRÉ FLUXO e 14,8 média de semanas do FGC20); e redução de 31\% na média de dias de intervalo total de tratamento, desde a primeira consulta até a realização da cirurgia (278,2 média de dias PRÉ FLUXO e 191,8 média de dias do FGC20). 
Houve redução de 8,9\% na média de dias de intervalo entre o início e o término da nCRT para o grupo FGC20 (43,9 média de dias do PRÉ FLUXO e 40 média de dias do FGC20). A dose total radioterápica utilizada foi a mesma em ambos os grupos, e outros fatores podem ter contribuído, como por exemplo, a necessidade de moldagem de blocos de colimação para os pacientes do grupo PRÉ FLUXO tratados em outro instituto, previamente à instalação do serviço de radioterapia no ICESP, prolongando o tempo entre o início e término da nCRT.

Uña \& López-Lara, 2010, avaliaram 48 pacientes tratados em protocolo clínico de tratamento de câncer de reto, comparados a 44 pacientes tratados anteriormente à implantação do protocolo. Encontraram melhoria dos intervalos de tempo para realização de colonoscopia, resultado de biópsia, primeiro tratamento e cirurgia em $100 \%$ dos pacientes que seguiram o protocolo. Porém, não demonstraram o quantitativo dos tempos obtidos ${ }^{6}$.

As diferenças encontradas entre os grupos em relação ao quantitativo de recursos utilizados refletem a adesão ao fluxograma estabelecido no FGC20. Houve racionalização de consultas de oncologista clínico, e incremento de consultas do cirurgião e da equipe multiprofissional. No grupo PRÉ FLUXO, observou-se nos registros de prontuário que o paciente era encaminhado ao cirurgião somente após o término do tratamento neoadjuvante, e vários retornos com oncologista eram feitos durante a espera entre as etapas do tratamento. O FGC20 sistematizou o acompanhamento conjunto entre oncologistas, cirurgiões e equipe multiprofissional. A adesão ao rol de exames estabelecidos no FGC20 é evidenciada pelo menor número de TC e RM, bem 
como pelo maior número de colonoscopias/retoscopias encontrado neste grupo. A uniformidade do protocolo de quimioterapia neoadjuvante utilizado (100\% protocolo FULV) e a redução das prescrições de quimioterapia de indução (1 caso) também sugerem adesão ao protocolo institucional, no grupo FGC20.

Levine et al, 2012, encontraram maior frequência de avaliações préoperatórias, aumento de acesso a consultas com oncologistas, e maiores taxas de tratamento neoadjuvante nos 88 pacientes com câncer colorretal atendidos na instituição, com conceito multidisciplinar, comparados a controle de 200 pacientes atendidos em outros serviços ${ }^{41}$.

Houve menor proporção de pacientes do grupo FGC20 com atendimentos pelo CAIO e UTI, evidenciando menor número de ocorrências de urgências e instabilidades clínicas neste grupo, sugerindo a hipótese de melhoria do manejo clínico com a implantação do FGC20.

O número de check films, para o controle de qualidade da radioterapia, foi maior no grupo FGC20. Atribui-se a diferença à tecnologia digital utilizada no grupo FGC20, que facilitava a sistematização de check films semanais.

Para a descrição de custos, foram considerados os recursos utilizados ao longo do período de tratamento: desde a primeira consulta médica, passando pela quimioterapia e radioterapia concomitantes, até a realização da cirurgia. Diárias e consultas representaram $58 \%$ do total do custo em ambos os grupos, sendo superiores aos procedimentos de tratamento oncológico propriamente ditos (cirurgia, radioterapia e quimioterapia), que representaram 
$42 \%$ do total. Para o paciente com câncer de reto, o atendimento de consultas representa $21 \%$ do total de custos do tratamento, refletindo um predomínio ambulatorial para o tratamento deste tumor.

A literatura é escassa em se tratando de estudos de avaliação econômica de protocolos clínicos ${ }^{43}$, e muitos apresentam os resultados de custos em relação a melhoria (ou não) da média de permanência hospitalar com a adoção dos mesmos ${ }^{47,48,49}$. Nestes, os custos considerados são os de cobrança hospitalar do período de internação. Archer et al, 1997, em protocolo clinico para pacientes de colectomia total, avaliaram 14 pacientes prospectivamente, comparados a 10 pacientes controle. Encontraram diminuição do tempo de permanência hospitalar e redução de custos hospitalares. Porém, não há descrição do custeio, e os valores representam o total da conta hospitalar ${ }^{49}$.

O presente estudo não se restringiu a uma etapa do tratamento, mas abrangeu todas as fases, pretendendo-se mensurar o custo do tratamento neoadjuvante do câncer de reto, na perspectiva do serviço. Atribuindo-se os valores unitários aos recursos utilizados por paciente, calculou-se o custo individual de cada paciente tratado, em ambos os grupos.

Como limitações à descrição de custos do tratamento, elenca-se: não inclusão de exames laboratoriais realizados ambulatorialmente, eletrocardiogramas e procedimentos ambulatoriais (retirada de pontos, curativos) pela dificuldade de obtenção desta informação; e falta de quantificação de medicamentos fornecidos aos pacientes pela farmácia ambulatorial. Exames e medicamentos prescritos em período de internação ou 
no centro cirúrgico foram considerados no cálculo do valor unitário das diárias de internação e do valor do minuto cirúrgico.

A literatura apresenta taxas de sobrevida global, correlacionando os períodos de análise em relação ao avanço das modalidades de tratamento para o câncer de reto. Estudo de Chang et al, 2012, avaliou 151 pacientes consecutivos, com diagnóstico de câncer de reto, tratados de 1993 a 2007, em uma única instituição. Foram comparados dois períodos: 1993 a 1999 e 2000 a 2007. Os autores observaram um aumento significativo no uso de tratamento neoadjuvante no segundo grupo, sem diferenças estatisticamente significantes na sobrevida global em 5 anos (86\% para o primeiro período e $78 \%$ para o segundo período $)^{50}$.

Resultado diferente foi mostrado por Wiegering et al, 2014. Os autores avaliaram dados de pacientes consecutivos com diagnóstico de câncer de reto, no período de 1993 a 2010, em uma única instituição. O estudo mostrou um aumento significativo de nCRT (17,6\% no período de 1993 - 2001 e $60 \%$ no período de 2002 a 2010), aumento da taxa de relato de ressecção total do mesorreto $(0,7 \%$ e $34,7 \%)$ e aumento da sobrevida global em 5 anos $(60,5 \%$ e $79,8 \%, p<0,0001)^{51}$.

Sineshaw et al, 2016, apresentaram taxas de sobrevida global segundo a modalidade de tratamento utilizada. Avaliaram dados de 28.550 pacientes com diagnóstico de adenocarcinoma de reto estádios II e III, entre 2004 e 2007, registrados no National Cancer Data Base, que congrega dados provenientes de 1500 programas de tratamento oncológico nos Estados Unidos, abrangendo aproximadamente $70 \%$ dos casos incidentes de câncer anuais. A taxa de 
sobrevida global em 5 anos foi de $72,4 \%, 70,9 \%, 44,9 \%$ e $48,8 \%$ para pacientes submetidos aos respectivos tratamentos: nCRT, quimioterapia e radioterapia adjuvantes, cirurgia exclusiva e quimioterapia e radioterapia exclusivas ${ }^{52}$.

No presente estudo, os grupos PRÉ FLUXO e FGC20 utilizaram as mesmas modalidades terapêuticas - nCRT e cirurgia - com resultados diferentes em relação à performance de tempo para conclusão do tratamento. Não se detectou diferenças estatisticamente significantes na sobrevida global entre os grupos para o período analisado. É necessário um período maior de acompanhamento para verificar o efeito destas melhorias em relação à sobrevida dos pacientes.

Comparar os dois grupos, PRÉ FLUXO e FGC20, possibilitou, portanto, verificar o impacto da implantação de um modelo de gerenciamento de protocolo clínico, em relação aos intervalos de tempo entre etapas do tratamento, aos recursos utilizados e aos custos associados ao tratamento do câncer retal. Estratégias como o FGC20 devem ser desenvolvidas e testadas, principalmente em protocolos de tratamento que envolvam diversas especialidades, situação muito encontrada nos tratamentos oncológicos atuais. 
CONCLUSÕES 


\section{CONCLUSÕES}

A implantação do Fluxo Gerenciado propiciou uma redução em todos os intervalos de tempo entre as etapas do tratamento, embora não tenha alterado a sobrevida global dos pacientes para o período analisado.

O FGC20 foi capaz de promover a otimização de recursos no processo terapêutico do câncer colo retal, sem implicar em um incremento no custo por paciente tratado. 
SUGESTÕES PARA TRABALHOS FUTUROS 


\section{SUGESTÕES PARA TRABALHOS FUTUROS}

Desenvolver estudos de análise de custo-efetividade a partir de dados primários, tais como os obtidos neste presente estudo. 
ANEXOS 


\section{ANEXOS}

\section{ANEXO Aprovação CEP-FMUSP}

Aprovação do Estudo “Avaliação da implementação do fluxo gerenciado FGC20, modelo de gerenciamento do protocolo clínico institucional para o tratamento neoadjuvante de adenocarcinoma de reto", pelo Comitê de Ética em Pesquisa da Faculdade de Medicina da Universidade de São Paulo. 


\title{
Hiflatili \\ MEDICINA \\ TSP \\ COMITÊ DE ÉTICA EM PESQUISA
}

\begin{abstract}
APROVAÇÃo
O Comitê de Ética em Pesquisa da Faculdade de Medicina da Universidade de São Paulo, em sessão de o7/05/2014, APROVOU o Protocolo de Pesquisa no 126/14 intitulado: "AVALIAÇÃO DA IMPLEMENTAÇÃo DO FLUXO GERENCIADO FGC2O, MODELO DE GERENCIAMENTO DO PROTOCOLO CLÍNICO INSTITUCIONAL PARA O TRATAMENTO NEOADJUVANTE DE ADENOCARCINOMA DE RETO." apresentado pelo Instituto do Câncer do Estado de São Paulo "Octávio Frias de Oliveira."

Cabe ao pesquisador elaborar e apresentar ao CEPFMUSP, os relatórios parciais e final sobre a pesquisa (Resolução do Conselho Nacional de Saúde $n^{\circ}$ 466/12).

Pesquisador (a) Responsável: Paulo Marcelo Gehm Hoff Pesquisador (a) Executante: Silvia T. Kobayashi
\end{abstract}

CEP-FMUSP, o9 de Maio de 2014.

$$
\text { PChaminn. }
$$

Prof. Dr. Roger Chammas

$$
\text { Coordenador }
$$

Comitê de Ética em Pesquisa 
REFERÊNCIAS BIBLIOGRÁFICAS 


\section{REFERÊNCIAS BIBLIOGRÁFICAS}

1. Cecílio LCO, Merhy EE. A integralidade do cuidado como eixo da gestão hospitalar. In: Pinheiro R, Mattos R. Construção da integralidade: cotidiano, saberes e práticas em saúde. Rio de Janeiro: IMS/Abrasco; 2003.

2. Merhy EE, Cecílio LCO. O singular processo de coordenação dos hospitais. Rev Saúde em Debate. 2003; 22(64):110-122.

3. Thomas R, Leigh K, Erica L J, Andreas M, Holger G, Jon W, Pamela S, Joachim K. Clinical pathways: effects on professional practice, patient outcomes, length of stay and hospital costs. Cochrane Database of Systematic Reviews. In: The Cochrane Library, Issue 3, Art. No. CD006632. DOI: 10.1002/14651858.CD006632.pub3.

4. Lopez-Lara F, Una Cidon E. Institucional implementation of a clinical pathway in rectal cancer: the advantages of standardization of protocols. Journal of Clinical Oncology. 2010; 28:15 suppl.1.

5. de Vries $M$, van Weert J C M, Jansen J, Lemmens V E P P, Maas H A A M. Step by step development of clinical care pathways for older cancer patients: necessary or desirable? European Journal of Cancer. 2007; 43:15 (2170-2178).

6. Uña E., López-Lara F. Pilot study of a clinical pathway implementation in rectal cancer. Clinical Medicine Insights: Oncology. 2010; 4 (111-115). 
7. Allen D, Rixson L. How has the impact of "care pathway technologies" on service integration in stroke care been measured and what is the strength of the evidence to support their effectiveness in this respect? Int J Evid Based Healthc. 2008; 6:78-110.

8. Cervantes A, Rodriguez-Braun E, Navarro S, Hernández A, Campos S, García-Granero E. Integrative decisions in rectal cancer. Annals of Oncology. 2007; 18 (supplement 9): ix127-ix131.

9. Gallego-Plazas J, Menárquez-Pina F, Maestre-Peiró A, González-Orozco V, Andreu F, Escudero-Bareal M J, Morcillo M A. Feasibility of adequate resectable rectal cancer treatment in a third-level hospital. Clin Transl Oncol. 2009; 11:172-177.

10.Eldin NS, Yasui $Y$, Scarfe A, Winget M. Adherence to treatment guidelines in stage II/III rectal cancer in Alberta, Canada. Clin Oncol ( $R$ Coll Radiol). 2012 Feb; 24(1):e9-17.

11. Morris E, Haward RA, Gilthorpe MS, Craigs C, Forman D. The impact of the Calman-Hine report on the processes and outcomes of care for Yorkshire's colorectal cancer patients. British Journal of Cancer. 2006; 95:979-985.

12. Drummond MF et al. Méthodes d’Évaluation Économique des Programmes de Santé.2.éd.Paris:Economica; 1998.

13. Brouselle A, Champagne F, Contandriopoulos AP, Hartz Z. Avaliação conceito e métodos. 1ª edição. Rio de Janeiro:Editora Fiocruz; 2011.

14. Novaes HMD. Pesquisa em, sobre e para os serviços de saúde: panorama internacional e questões para a pesquisa em saúde no Brasil. Cad. Saúde Pública, Rio de Janeiro. 2004; 20 Sup 2:S147-S173. 
15.Weiss $\mathrm{CH}$. Evaluation Research: methods for assessing program effectiveness. Englewood Cliffs, Prentice-Hall; 1972c.

16.Wholey JS. Evaluability assessment: developing program theory. San Francisco: Jossey-Bass Publishers; 1987.

17. Chen HT. Theory Driven Evaluations. Newbury Park: Sage Publications; 1990.

18. Le Moigne JL. La Modélisation des Systèmes Complexes. Paris: Dunod; 1990.

19.Jemal A, Bray F, Center MM, Ferlay J, Ward E, et al. Global cancer statistics. CA Cancer J Clin. 2011; 61:69-90.

20. Meyerhardt JA, Niedzwiecki D, Hollis D et al. Association of dietary patterns with cancer recurrence and survival in patients with stage III colon cancer. JAMA. 2007; 298:754-64.

21.Beresford SA, Johnson KC, Ritenbaugh C et al. Low-fat dietary pattern and risk of colorectal cancer: the Women's Health Initiative Randomized Controlled Dietary Modification Trial. JAMA. 2006; 295:643-54.

22. Park Y, Hunter DJ, Spiegelman D et al. Dietary fiber intake and risk of colorectal cancer: a pooled analysis of prospective cohort studies. JAMA. 2005; 294:2849-57.

23. Wilschut JA, Habbema JD, Ramsey SD et al. Increased risk of adenomas in individuals with a family history of colorectal cancer: results of a meta-analysis. Cancer Causes Control. 2010; 21:2287-93.

24. Hoff PMG, Katz A, Chammas R, Odone Filho V, Novis YS. Tratado de Oncologia. São Paulo: Editora Atheneu; 2013. 
25.Baxter NN, Tepper JE, Durham SB et al. Increased risk of rectal cancer after prostate radiation: A population-based study. Gastroenterology. $2005 ; 128: 819-24$

26. Gastrointestinal Tumor Study Group. Prolongation of the disease-free interval in surgically treated rectal carcinoma. $N$ Engl J Med. 1985; 312:1465-72.

27.Fisher B, Wolmark N, Rockette $\mathrm{H}$ et al. Postoperative adjuvant chemotherapy or BCG for colon cancer: results from NSABP Protocol R01. J Natl Cancer Inst. 1988; 80:21-9.

28. Heald RJ, Ryall RD. Recurrence and survival after total mesorectal excision for rectal cancer. Lancet. 1986; 1(8496):1479-82.

29. Heald RJ, Husband Em, Ryall RD. The mesorectum in rectal cancer surgery: the clue to pelvic recurrence? Br J Surg. 1982; 69:613-6.

30.Sauer J, Sobolewski K, Dommisch K. Practical neoadjuvant and adjuvant therapies for rectal cancer. How many patients are actually recruited in multimodality therapy concepts? An analysis of the Tumor Centre Schewerin. Zentralb/ Chir. 2009 Sep; 134(5):450-4.

31. Augestad K M, Lindsetmo R O, Stulberg J, Reynolds $H$, Senagore A, Champagne B, Heriot A G, Leblanc F, Delaney C P, IRCSG. International preoperative rectal cancer management: staging, neoadjuvant treatment, and impact of multidisciplinar teams. World $J$ Surg. 2010 November; 34(11):2689-2700.

32. Swellengrebel H A M, Peters E G, Cats A, Visser O, Blaauwgeers H G T, Verwaal V J, van Velthuysen M L, Cense H A, Bruin S C, Marijnen C A M. Multidisciplinary discussion and management of rectal cancer: a 
population-based study. World J Surg. 2011 September; 35(9): 21252133.

33. Meredith K L, Hoffe S E, Shibata D. The multidisciplinar management of rectal cancer. Surg Clin North Am. 2009 Feb; 89(1):177-215, ix-x.

34.ICESP - Instituto do Câncer do Estado de São Paulo. Manual de Condutas em Oncologia. 1ㄹedição, São Paulo: Imprensa Oficial do Estado de São Paulo; 2010.

35. Hoff PM, Diz MDPE, Pereira J. Manual de Condutas em Oncologia. 2ª̣edição, São Paulo: Editora Atheneu; 2013.

36. Ribeiro Junior U, Kulcsar MAV. Manual de Condutas em Oncologia Cirúrgica. São Paulo: Editora Atheneu; 2013.

37.Bosset, J.F., Collete, L., Calais, G. et al. (2006) Chemotherapy with preoperative radiotherapy in rectal cancer. N Engl J Med, 355:1114-23.

38. Benson III AB, Bekaii-Saab T, Chan E, Chen Y-J, Choti MA, Cooper HS, Engstrom PF, Enzinger PC, Fakih MG, Fuchs CS, Grem JL, Hunt S, Leong LA, Lin E, Martin MG, May KS, Mulcahy MF, Murphy K, Rohren E, Ryan DP, Saltz L, Sharma S, Shibata D, Skibber JM, Small Jr W, Sofocleous CT, Venook AP, Willett CG, Freedman-Cass DA, Gregory KM. Rectal cancer (Review). Journal of the National Comprehensive Cancer Network. 2012 Dec; 10(12):1528-1564.

39. Obias VJ, Reynolds Jr HL. Multidisciplinary Teams in the Management of Rectal Cancer. Clinics in Colon and Rectal Surgery. 2007; 3(20):143147. 
40. Fleissig A, Jenkins V, Catt S, Fallowfield L. Multidisciplinary teams in cancer care: are they effective in the UK? (Review). Lancet Oncology. 2006 Nov; 7(11):935-943.

41.Levine RA, Chawla B, Bergeron S, Wasvary H. Multidisciplinary management of colorectal cancer enhancer access to multimodal therapy and compliance with National Comprehensive Cancer Network (NCCN) Guidelines (Review). International Journal of Colorectal Disease. 2012 Nov; 27 (11):1531-1538.

42.Chang KH, Smith MJ, McAnena OJ, Aprjanto AS, Dowdall JF. Increased use of multidisciplinar treatment modalities adds little to the outcome of rectal cancer treated by optimal total mesorectal excision. International Journal of Colorectal Disease. 2012 Oct; 27(10):1275-1283.

43. Allen D, Gillen E, Rixson L. Systematic review of the effectiveness of integrated care pathways: what works, for whom, in which circumstances? Int J Evid Based Healthc. 2009; 7: 61-74.

44. Rossi PH, Freeman HE \& Lipsey MW. Evaluation: a systematic approach. $6^{\mathrm{a}}$ ed. Thousand Oaks, CA:Sage Publications; 2004a.

45.Weiss $\mathrm{CH}$. Nothing as practical as good theory: exploring theory-based evaluation for comprehensive community initiatives for children and families. Washington: Aspen Institute; 1995.

46. Ludt S, Urban E, Eckardt J, Wache S, Broge B, et al. Evaluating the Quality of Colorectal Cancer Care across the Interface of Healthcare $\begin{array}{lllll}\text { Sectors. } & \text { PLoS } & & \end{array}$ doi:10.1371/journal.pone.0060947. 
47.Kennedy EP, Grenda TR, Sauter PK, Rosato EL, Chojnacki KA, Rosato FE Jr, Profeta BC, Doria C, Berger AC, Yeo CJ. Implementation of a critical pathway for distal pancreatectomy at an academic institution. $J$ Gastrointest Surg. 2009 May; 13(5):938-44.

48. Yueh B, Weaver EM, Bradley EH, Krumholz HM, Heagerty P, Conley A, Sasaki CT. A critical evaluation of critical pathways in head and neck cancer. Arch Otolaryngol Head Neck Surg. 2003 Jan; 129(1):89-95.

49. Archer SB, Burnett RJ, Flesch LV, Hobler SC, Bower RH, Nussbaum MS, Fischer JE. Implementation of a clinical pathway decreases length of stay and hospital charges for patients undergoing total colectomy and ileal pouch/anal anastomosis. Surgery. 1997 Oct; 122(4):699-703; discussion 703-5.

50. Chang $\mathrm{K} \mathrm{H}$, Smith $\mathrm{M} \mathrm{J}$, McAnena $\mathrm{O} \mathrm{J}$, Aprjanto A S, Dowdall J F. Increased use of multidisciplinar treatment modalities adds little to the outcome of rectal cancer treated by optimal total mesorectal excision. Int J Colorectal Dis. 2012; 27: 1275-83.

51.Wiegering A, Isbert C, Dietz U A, Kunzmann V, Ackermann S, Kerscher A, Maeder U, Flentje M, Schlegel N, Reibetanz J, Germer C T, Klein I. Multimodal therapy in treatment of rectal cancer is associated with improved survival and reduced local recurrence - a retrospective analysis over two decades. BMC Cancer. 2014; 14:816.

52. Sineshaw H M, Jemal A, Thomas Jr CR, Mitin T. Changes in treatment patterns for patients with locally advanced rectal cancer in the United States over the past decade: an analysis from the National Cancer Data Base. Cancer. 2016 July; 1: 1996-2003. 